Published in final edited form as:

Continuum (Minneap Minn). 2018 October ; 24(5 NEUROINFECTIOUS DISEASE): 1298-1326. doi: 10.1212/CON.0000000000000664.

\title{
Chronic Meningitis
}

\section{Kiran T. Thakur, MD, Michael R. Wilson, MD, MAS}

\section{Abstract}

PURPOSE OF REVIEW: This article describes the clinical presentation, diagnostic approach (including the use of novel diagnostic platforms), and treatment of select infectious and noninfectious etiologies of chronic meningitis.

RECENT FINDINGS: Identification of the etiology of chronic meningitis remains challenging, with no cause identified in at least one-third of cases. Often, several serologic, CSF, and neuroimaging studies are indicated, although novel diagnostic platforms including metagenomic deep sequencing may hold promise for identifying organisms. Infectious etiologies are more common in those at risk for disseminated disease, specifically those who are immunocompromised because of human immunodeficiency virus (HIV)/acquired immunodeficiency syndrome (AIDS), transplantation, or immunosuppressant medications. An important step in identifying the etiology of chronic meningitis is assembling a multidisciplinary team of individuals, including those with specialized expertise in ophthalmology, dermatology, rheumatology, and infectious diseases, to provide guidance regarding diagnostic procedures.

SUMMARY: Chronic meningitis is defined as inflammation involving the meninges that lasts at least 4 weeks and is associated with a CSF pleocytosis. Chronic meningitis has numerous possible infectious and noninfectious etiologies, making it challenging to definitively diagnose patients. Therefore, a multifaceted approach that combines history, physical examination, neuroimaging, and laboratory analysis, including novel diagnostic platforms, is needed. This article focuses on key aspects of the evaluation of and approach to patients with chronic meningitis. Specific infectious etiologies and differential diagnoses of subacute and chronic meningitis, including noninfectious etiologies, are addressed.

\section{INTRODUCTION}

Meningitis involves inflammation of any of the three layers of the meninges and is often described according to the clinical time course. Chronic meningitis is differentiated clinically from acute and subacute meningitis by an arbitrary time point of more than 4 weeks of clinical symptoms with evidence of a CSF pleocytosis. ${ }^{1}$ The underlying causes of acute and chronic meningitis differ, with community-acquired bacteria and viruses more common in acute meningitis and atypical bacteria, endemic fungi, and noninfectious etiologies more common in chronic meningitis. Establishing a cause of chronic meningitis

Address correspondence to Dr Kiran T. Thakur, Division of Critical Care and Hospitalist Neurology, Department of Neurology, Columbia University Medical Center, 177 Fort Washington Ave, Milstein Hospital, 8GS-300, New York, NY 10032, ktt2115@cumc.columbia.edu.

UNLABELED USE OF PRODUCTS/INVESTIGATIONAL USE DISCLOSURE:

Drs Thakur and Wilson report no disclosures. 
and providing timely targeted treatment are major challenges for clinicians as many identified infectious agents are rare, and noninfectious etiologies, including medications, neuroinflammatory conditions, toxins, and malignancy, mimic infectious etiologies. The list of possible diagnoses, particularly in high-risk patients, including those who are immunocompromised, is expansive, with the three most common etiologies of chronic meningitis being fungal infections, tuberculosis, and neoplasm.

The complexity of diagnosing cases is illustrated by a report summarizing the diagnostic testing of 37 patients with chronic idiopathic meningitis evaluated at the Mayo Clinic. Despite over 2000 tests ordered on the CSF of these patients, a diagnosis was made in less than half of patients. ${ }^{2}$ In general, over one-third of cases remain undiagnosed by traditional diagnostic testing approaches. ${ }^{3}$ The development of novel noninvasive diagnostic techniques, including multiplex polymerase chain reaction (PCR); 16s, 18s, and 28s ribosomal RNA (rRNA) PCR; and metagenomic deep sequencing, allowing for broad pathogen testing, is an exciting scientific frontier. 4,5 The latter two are more "unbiased" techniques that may hold particular promise in complex chronic meningitis cases in which the differential diagnosis is broad.

This article proposes an approach to evaluating patients with chronic meningitis, discusses novel diagnostic platforms, highlights several infectious and noninfectious etiologies, and discusses conditions that are of particular relevance to patients with recurrent meningitis.

\section{CLINICAL APPROACH}

The first step in the approach to patients with chronic meningitis is to establish the time course of the illness. Defining the date of onset often proves to be challenging, as patients may have trouble clarifying the onset of vague symptoms that occurred weeks before a more fulminant symptomatic presentation. ${ }^{1}$ Patients and physicians often attribute initial neurologic symptoms to chronic conditions such as migraine, although the astute clinician will elicit differences in the phenomenology of symptoms. A thorough historical account of neurologic symptoms and a review of systems must be performed in all patients. It is essential that clinicians attempt to develop a thorough timeline of the progression of symptoms as patterns can be particularly significant (refer to the Recurrent Meningitis section). Diagnostic clues may be identified on social history, including risk factors for sexually transmitted diseases. The immune status and immunization history of all patients should be evaluated through both history and laboratory testing. A careful review of all recent medications is required as several medication categories (eg, IV immunoglobulin [IVIg], nonsteroidal anti-inflammatory medications) can lead to chronic meningitis (refer to the Chemical Etiologies section). A thorough epidemiologic history should be obtained, including travel history, vocational history, and hobbies. Possible nosocomial exposures in health care workers or exposures in prison workers should be evaluated. Exposure to animals, toxins, or sick contacts and the possible consumption of raw or poorly cooked food are essential historical features. The presence of systemic symptoms or signs, including skin rash, joint pains, or mouth/genital ulcers, may provide diagnostic clues (TABLE $\left.3-1^{6}\right){ }^{7}$ Specialist opinions may be very useful during the assessment for an etiology. Ophthalmologists can evaluate for the presence of eye involvement of infectious processes 
or ocular signs of neuroinflammatory conditions; rheumatologists can assess for underlying joint or musculoskeletal clues that may be related to central nervous system (CNS) manifestations; and infectious disease colleagues, especially those with expertise in transplant medicine and tropical diseases, can assist with the evaluation and often provide access to advanced serologic testing through the local health department or the Centers for Diseases Control and Prevention (CDC). Public health experts are important resources as they can provide information on emerging infections, diagnostic testing approaches, and the availability of specialized diagnostic studies at local and national public health laboratories. The authors recommend that multidisciplinary evaluations occur early in the clinical workup.

\section{Traditional Diagnostic Testing}

Diagnostic testing should be guided by a thorough history, including assessment of epidemiologic factors and physical examination findings. Typically, an exhaustive list of possible serologic and CSF studies is developed and neuroimaging is obtained. ${ }^{7}$ Rather than sending a comprehensive list of diagnostic tests for all etiologies of chronic meningitis, the authors suggest that clinicians take into account several factors when testing for possible etiologies, including whether the patient is immunocompromised; has a history of suspected or known neuroinflammatory condition or malignancy, or systemic features; whether the patient has traveled to or lived in a foreign country with possible infectious exposures; and neuroimaging characteristics (FIGURE 3-1 ${ }^{8}$ ). Neuroimaging features, in particular the pattern of meningeal enhancement (ie, pachymeningeal, leptomeningeal, basal meningeal) can be helpful in narrowing the differential diagnosis (FIGURE 3-2, TABLE 3-2, TABLE 3-3). ${ }^{9}$ This approach must weigh the clinical picture of the patient, as patients who are critically ill should obtain an expedited broader workup. Patients often require multiple lumbar punctures (LPs), and the authors recommend that three samples of at least $10 \mathrm{~mL}$ of CSF be sent at different time points for diagnostic testing for specific etiologies, including tuberculous meningitis, fungi, and neoplasm (especially lymphoma). Centrifugation of CSF samples and lengthening the time of microscopic examination increase the diagnostic yield of certain infectious organisms, particularly fungal and mycobacterial pathogens. ${ }^{10,11}$ The basic CSF findings in chronic meningitis are variable based on etiology; they may also vary depending on the timing of CSF analysis with respect to symptom onset. For example, early in tuberculous meningitis and certain fungal infections, the CSF may have a neutrophilic pleocytosis that transitions later to a lymphocytic pleocytosis. ${ }^{12}$ Low CSF to serum glucose and elevated opening pressure are suggestive of infection with atypical bacteria or fungal infections but also may be seen in subarachnoid neurocysticercosis, neurosarcoidosis, and carcinomatous meningitis. ${ }^{7}$ Meningeal and/or brain biopsy may be valuable, especially in cases in which areas of enhancement are identified on postcontrast MRI. In one case series involving 37 patients with chronic meningitis of unknown etiology, a definitive diagnosis was made in $39 \%$ of patients, with a diagnostic etiology identified in $80 \%$ of cases with enhancement versus $9 \%$ in those with no evidence of enhancement. ${ }^{13}$

\section{Novel Diagnostic Testing Approaches}

Given the limitations of traditional diagnostic testing approaches and the often-dire consequences of an undiagnosed infection, recent diagnostic developments are an exciting 
frontier for patients with chronic infectious meningitis. The 16s rRNA gene is a highly conserved region in bacteria, whereas the 18s and 28s rRNA genes are highly conserved in fungi. As a result, PCR with primers to these microbial genes makes it possible to identify a variety of bacterial and fungal species. In culture-proven cases of meningitis, 16s rRNA PCR was $94 \%$ sensitive and specific. Importantly, it was positive in $30 \%$ of culture-negative cases. ${ }^{14}$ In another study, $16 \mathrm{~s}$ and $18 \mathrm{~s}$ rRNA PCRs were $65 \%$ sensitive compared to $35 \%$ sensitivity with microscopy and culture. The main reason for discordance was pretreatment with antibiotics before LP, leading to diminished culture results. ${ }^{15}$

In addition to a growing number of case reports, a recent case series of seven patients with chronic meningitis documented the ability of CSF metagenomic deep sequencing to identify a variety of viral, parasitic, and fungal causes of chronic meningitis. ${ }^{16-22}$ Metagenomic deep sequencing is a fundamentally different diagnostic modality given that it interrogates all the nucleic acid present in a tissue sample rather than querying the sample with a set of probes that are specific for an organism on the treating physician's differential diagnosis. Once the nonhuman sequences are computationally culled from the larger data set, these nonhuman DNA or RNA sequences are searched against giant, publicly available databases to determine the identity of the nonhuman species present in the tissue sample. Hence, metagenomic deep sequencing is an agnostic, or hypothesis-free, approach that does not require a priori consideration of a particular organism for it to be identified in the resulting genomic data set. While larger prospective studies are needed to determine the clinical utility and performance of this new diagnostic modality (which recently became clinically validated for CSF), infectious cases of chronic meningitis may be particularly suited to this assay. It is well recognized that microbial nucleic acid is typically present for only a matter of days in many acute neuroinvasive infections, so the sensitivity of pathogen-specific PCR and metagenomic deep sequencing can be critically dependent on the timing of the CSF sample being interrogated, whereas diagnosis with direct detection methods, such as metagenomic deep sequencing in CSF from a patient with a chronic infection, will be less time sensitive. In addition, to the degree that metagenomic deep sequencing testing can be shown to be sufficiently sensitive in ongoing prospective studies, a negative CSF metagenomic deep sequencing result may enable more rapid initiation of empiric immunosuppression when a noninfectious etiology is clinically favored.

\section{General Treatment Approaches}

It is widely accepted that in presumptive acute meningitis cases, clinicians should provide rapid empiric antimicrobial treatment to avoid the significant associated morbidity and mortality, with coverage for causes of community-acquired bacterial meningitis in the general population and broader coverage in patients who are immunocompromised. This strategy differs in patients who present with more chronic symptoms. Because of the frequently indolent nature of the symptoms associated with chronic meningitis, the rarer and more diverse infectious causes, and the significant number of noninfectious etiologies, empiric treatment for chronic meningitis is not broadly recommended. Instead, it is recommended that empiric therapy be initiated on a case-by-case basis after weighing the risks and benefits associated with antimicrobial therapy and the potential for a worsening clinical course. An important point to note is that clinicians should have a low threshold to 
initiate empiric antimicrobial therapy in those who are neutropenic or have acquired immunodeficiency syndrome (AIDS) and in patients who are posttransplantation, given the risk for fulminant infection with significant morbidity and mortality. It should be noted that because many empiric treatment regimens for chronic meningitis include adjunctive glucocorticoids, an early therapeutic response must be interpreted with caution given the temporary clinical benefit many patients may experience from steroids alone.

\section{INFECTIOUS ETIOLOGIES}

Infectious causes of chronic meningitis include fungi, viruses, bacteria, and parasites.

\section{Fungal Etiologies}

Several fungi can cause chronic meningitis, with Cryptococcus species being the most common. Other fungal etiologies include the endemic fungi Histoplasma, Blastomyces, and Coccidioides as well as Aspergillus and Candida species. ${ }^{23}$ This section provides an overview of the fungal infections most frequently associated with chronic meningitis and discusses implications of the fungal meningitis outbreak due to steroid injections that occurred in 2012 in the United States.

CRYPTOCOCCAL MENINGITIS.-Cryptococcus remains the most common fungal etiology of chronic meningitis globally. ${ }^{24}$ The CDC estimates that in regions with a significant burden of human immunodeficiency virus (HIV)/AIDS, cryptococcal meningitis is a major contributor to morbidity and mortality, with at least 100,000 deaths annually in sub-Saharan Africa alone. ${ }^{25,26}$ Other forms of immunosuppression are important risk factors for cryptococcal meningitis, including transplantation, malignancy, and idiopathic $\mathrm{CD}_{4+}$ lymphocytopenia. ${ }^{27}$ The most common cryptococcal species causing chronic meningitis in the immunosuppressed population is Cryptococcus neoformans. C. neoformans has a global distribution and is found in contaminated soil, bird excrement, and tree bark (CASE 3-1). ${ }^{23}$ Notably, patients who are immunocompetent are at risk of chronic meningitis due to Cryptococcus gattii, which has been identified in outbreaks in British Columbia and the Pacific Northwest. ${ }^{28}$ Patients with HIV may have more rapid clinical deterioration than those who are not HIV infected; they are at high risk for early progression to coma and death due to elevated intracranial pressure (ICP). ${ }^{29}$ Swift and repeated treatment to decrease ICP and targeted antifungal treatment are essential in all patients. Unfortunately, despite antifungal treatment, studies continue to show mortality rates of at least $25 \% .{ }^{30}$

The CSF in cryptococcal meningitis is characterized by a lymphocytic pleocytosis, elevated CSF protein, and low CSF to serum glucose. In patients with cryptococcal meningitis who are immunocompromised, the CSF profile may be bland with a near-normal CSF white blood cell count and protein. ${ }^{31}$ Fungal culture is highly sensitive and can be useful for both diagnosing infection and for organism identification, although culture growth can be slow and false-negative results occur. ${ }^{32}$ The diagnostic yield is increased when a large volume of CSF is tested, especially in cases with a low fungal burden. India ink microscopy is a lowcost technique often used in resource-limited settings, although, as with fungal culture, it can be falsely negative in cases with a low CSF fungal burden. ${ }^{33}$ Cryptococcal antigen in the CSF is highly sensitive and specific, and it is recommended as the primary test to rapidly 
diagnose cryptococcal meningitis cases. ${ }^{34}$ The cryptococcal antigen lateral flow assay is a new test that is particularly appealing in resource-limited settings as it does not require storage, is low-cost, and provides rapid results. ${ }^{33}$

Serum cryptococcal antigen testing should not be used to rule out cryptococcal meningitis, although serum cryptococcal antigen screening may be useful in high-risk populations as it is detectable at least a few weeks before the onset of neurologic symptoms. ${ }^{35}$ Indeed, the World Health Organization advocates a "screen and treat" approach with oral fluconazole in $\mathrm{HIV}$-infected patients with a $\mathrm{CD}_{4+}$ count lower than 100 cells $/ \mathrm{mm}^{3}$ in regions where the burden of cryptococcal antigenemia is high to preempt the development of cryptococcal meningitis independent of whether patients are symptomatic or not. ${ }^{36}$ In this scenario, patients who test positive for serum cryptococcal antigen should be screened for neurologic symptoms and an LP should be performed for CSF diagnostic studies. Even if an LP cannot be performed, presumptively treating these high-risk patients not just with prophylactic fluconazole but with combination antifungal therapy for cryptococcal meningitis can be considered, as one-third of asymptomatic patients with cryptococcal antigen-positive serum in a 2018 study were found to have cryptococcal meningitis, and $90 \%$ of patients whose only symptom was a headache were also found to have cryptococcal meningitis. ${ }^{37}$ In any patient with concurrent untreated HIV infection and cryptococcal meningitis, antiretroviral therapy (ART) initiation should be delayed to minimize the risk of the potentially fatal complication of cryptococcal meningitis immune reconstitution inflammatory syndrome. Evidence for this comes from the Timing of Antiretroviral Therapy After Diagnosis of Cryptococcal Meningitis trial performed in Africa, which showed that delaying the initiation of ART for more than 4 weeks after initiation of induction cryptococcal meningitis therapy was associated with improved survival, compared with early initiation of ART at 1 to 2 weeks. ${ }^{38}$

Treatment for those with proven cryptococcal meningitis should follow a three-step approach with induction, consolidation, and maintenance phases. For the induction phase, amphotericin B with flucytosine has been shown to decrease mortality over amphotericin B alone. While 2 weeks of therapy is traditionally recommended, access to antifungal treatment in regions with the highest burden of cryptococcal meningitis is a major challenge. A recent study in Africa identified alternative treatment regimens, with evidence that 1 week of amphotericin B with flucytosine or the all-oral regimen of 2 weeks of fluconazole with flucytosine was as effective as the standard 2-week induction treatment in resource-limited settings. ${ }^{39}$ Consolidation therapy with fluconazole for at least 8 weeks is recommended, followed by maintenance therapy with lower-dose fluconazole for a minimum of 1 year. ${ }^{40}$ Antifungal treatment for cryptococcal infection in patients who are HIV infected should be lifelong or until the immune system has recovered with ART to a $\mathrm{CD}_{4+} \mathrm{T}$-cell count of greater than 200 cells $/ \mathrm{mm}^{3} .40$

Adjunctive steroid use was investigated in a 2016 randomized trial, with dexamethasone not shown to impact morbidity or mortality among patients with HIV infection who have cryptococcal meningitis. In fact, patients who received adjunctive glucocorticosteroids were less likely to have a good neurologic outcome and had significantly slower rates of fungal clearance. ${ }^{41}$ Thus, current recommendations do not advocate treatment with adjunctive steroids in cases of definitive cryptococcal meningitis, especially in those who are HIV 
positive. In parallel with antifungal treatment, increased intracranial pressure should be aggressively treated with daily therapeutic LPs to reduce the opening pressure by at least $50 \%$ until normalization of CSF opening pressure. A lumbar drain or ventriculostomy may be considered in select patients undergoing frequent therapeutic LPs with persistently elevated opening pressure. ${ }^{42}$ This should be considered on a case-by-case basis given the infection risks associated with device placement. Importantly, aggressive measures to decrease ICP improve survival by up to $70 \%$. Despite these recommendations, therapeutic LPs are underutilized, as a study in Uganda showed a strikingly low rate of therapeutic LPs performed in patients with cryptococcal meningitis. ${ }^{43}$ Despite antifungal treatment, studies have shown long-term mortality is at least $25 \% .{ }^{44}$

HISTOPLASMOSIS.-Histoplasma infections are classically associated with the epidemiologic risk factor of dwelling in or travel around the Ohio and Mississippi River valleys, although it is important that clinicians recognize that the fungus is globally distributed. ${ }^{45}$ Indeed, in the United States, the highest rates of infection occur in the Midwestern states, with Histoplasma identified in soil, frequently associated with bird or bat droppings. ${ }^{45-48}$ While histoplasmosis infections are most commonly associated with pulmonary signs and symptoms, including pleural disease, cavitary lesions, and mediastinal involvement, CNS disease does occur, most commonly in association with disseminated infection. ${ }^{45} \mathrm{CNS}$ involvement is identified in up to one-fourth of disseminated cases on autopsy studies, with the immunocompromised population at highest risk. ${ }^{49} \mathrm{Chronic}$ meningitis most commonly presents with basal meningeal involvement and typically occurs in the context of hematogenous spread to the meninges. ${ }^{48}$ The CSF profile parallels other fungal infections, with elevated CSF protein, low CSF to serum glucose, and a moderate lymphocytic and monocytic predominant pleocytosis. ${ }^{50}$ In addition to a thorough neurologic examination, patients should undergo a systemic evaluation for features of disseminated infection, including hepatosplenomegaly, ocular involvement, lymphadenopathy, and pulmonary findings of cavitary lesions. ${ }^{49}$ Multiple diagnostic modalities are often required to identify the organism in patients with chronic meningitis, as CSF culture is positive in less than $50 \%$ of cases, with significant delays being common because of slow growth. Rather than relying solely on CSF culture, all patients with suspicion of CNS histoplasmosis should have CSF antigen and antibody testing performed, which is positive in at least $50 \%$ of cases. ${ }^{51}$ If disseminated infection is suspected, ancillary testing of the urine and serum for Histoplasma antigen should be performed, and tissue biopsy samples may be diagnostic. ${ }^{52}$ The optimal treatment of CNS histoplasmosis is unknown, as no prospective studies have been conducted from which an evidence-based approach can be formulated. General consensus is to give amphotericin B for induction therapy for at least 3 months, with the Infectious Diseases Society of America (IDSA) recommending either fluconazole or itraconazole as possible treatment agents following induction. ${ }^{53}$ Hydrocephalus may complicate histoplasmosis meningitis and, when present, should lead to consideration of ventricular shunt placement. Ideally, this should be delayed until the patient has received at least a few weeks of amphotericin B to reduce the likelihood of shunt colonization. ${ }^{52}$

BLASTOMYCOSIS.-Blastomyces species are found in the soil in the Southeast, South Central, and Great Lakes regions of the United States and Canada and are endemic in parts 
of Africa. ${ }^{54}$ As with histoplasmosis, pulmonary symptoms are the most frequent clinical manifestation and can be severe, with risk of acute respiratory distress syndrome, particularly in patients who are immunocompromised. ${ }^{55,56}$ Extrapulmonary disease is frequently associated with skin, bone, and genitourinary system involvement. The skin is the most commonly affected site after the lungs, and skin involvement is a major diagnostic clue of disseminated blastomycosis infection, with pustular lesions that later crust over commonly found on the face and neck. ${ }^{54}$ Neurologic involvement occurs in less than $10 \%$ of patients. ${ }^{57} \mathrm{~A}$ basilar meningitis is most frequent, with poor prognosis associated with development of ventriculitis and hydrocephalus. Definitive diagnosis requires culture growth or characteristic histopathologic findings from brain biopsy or extraneural tissue biopsy. Isolation from CSF culture occurs in less than $50 \%$ of cases, with large volumes and ventricular fluid sampling increasing sensitivity. ${ }^{58}$ Detection of Blastomyces dermatitidis antigen is a useful diagnostic assay, although cross-reactivity can occur with other fungal infections, including histoplasmosis. A 2018 case report showed the utility of CSF testing for Blastomyces antigen with a quantitative antigen enzyme immunoassay, which is now commercially available. .5

Evidence-based guidelines for treatment are limited by a lack of prospective studies. Current recommendations include treatment with amphotericin B for at least 1 month followed by an oral azole, with the IDSA treatment guidelines recommending itraconazole. Antifungal treatment should be continued until clinical stability is achieved and CSF parameters normalize. More than 1 year of therapy is typically required. ${ }^{60}$

COCCIDIOIDOMYCOSIS.-Coccidioidomycosis is caused by the fungi Coccidioides immitis and Coccidioides posadasii, both of which are endemic to warm, dry regions, including the southwestern United States, Mexico, and Central America. High-risk groups include agricultural and construction workers, who are frequently exposed to airborne spores from the soil. ${ }^{61}$ As with other endemic fungi, pulmonary manifestations are the most common clinical presentation and are most frequently seen as a community-acquired pneumonia. ${ }^{62}$ Disseminated disease occurs in a small minority of patients (an estimated 1\%) and most commonly involves the skin, subcutaneous tissues, musculoskeletal system, and the meninges, with higher risks of severe or disseminated coccidioidomycosis in women who are pregnant and patients who are elderly, immunocompromised, or of Filipino and African American ethnicity. ${ }^{61}$ Coccidioidal meningitis is most commonly associated with disseminated disease and is usually a granulomatous infection involving the basilar cistern. Meningitis can be associated with brain abscesses and a vasculitis causing ischemic strokes and hemorrhage. ${ }^{63-65} \mathrm{~A}$ unique feature of the CSF in CNS coccidioidomycosis is the presence of eosinophils, although these are not present in all cases. ${ }^{66}$ Fungal culture and visualization of spores in the CSF or biopsy specimens confirm the diagnosis, although prior studies have shown positive results in less than $30 \%$ of cases. Clinicians often rely on serologic testing for anticoccidioidal IgM and IgG antibodies because of the limitations of culture and histopathology. Several methods are available for serology testing, including via complement fixation and enzyme immunoassay, although it is notable that false-negative and false-positive results are seen, depending on technique. ${ }^{67}$ The overall sensitivity of antibody testing is approximately $70 \%{ }^{68,69}$ Therefore, the authors recommend that in all patients 
with a suspicion of coccidioidomycosis meningitis, CSF antibody and antigen testing should be sent in addition to traditional testing. A urine and serum antigen test can aid in diagnosing coccidioidomycosis and should be sent on patients suspected of having disseminated disease. $^{70}$

Up to $40 \%$ of patients develop hydrocephalus, and the authors recommend aggressive management, including daily LPs or consideration of shunt if hydrocephalus is refractory to multiple therapeutic LPs. ${ }^{71}$ The disease is recurrent and fatal without lifelong treatment; thus, IDSA guidelines recommend lifelong azole treatment. ${ }^{72}$

ASPERGILLOSIS.-Aspergillosis is an opportunistic fungal infection with global distribution that is acquired through inhalation of spores. Disseminated disease occurs in patients who are immunocompromised, most notably in transplant recipients. ${ }^{73}$ Aspergillosis is angioinvasive, and neurologic manifestations most frequently involve a CNS vasculitis of small and medium-sized arteries. ${ }^{74,75}$ Meningeal involvement is a less common complication and, when present, is typically associated with vasculitis and brain abscesses. 75,76 Invasive CNS aspergillosis involving the meninges may also result from direct invasion from adjacent sinonasal structures, although this occurs much more rarely than hematogenous spread (CASE 3-2). For diagnosis, CSF culture is rarely positive. ${ }^{77}$ Aspergillus PCR is a promising technique that has high sensitivity and specificity in serum. ${ }^{78}$ In a recent small study, CSF Aspergillus PCR was 75\% sensitive, although larger studies are needed to establish the utility of CSF PCR for diagnosis of CNS aspergillosis. ${ }^{79,80}$ Elevated CSF galactomannan has been shown to have a sensitivity of over $80 \%$ and is recommended in patients for whom a strong clinical suspicion exists. ${ }^{79,80} \mathrm{CSF}(1,3)$-b-D-glucan, which is a cell wall component of several fungal species, is also recommended as an adjunctive test, although it is not specific for aspergillosis (refer to the section on the 2012-2013 US fungal meningitis outbreak). ${ }^{81}$ Brain biopsy is often needed to provide microbiological culture and histologic information; it has particularly high yield when a brain abscess is present. Invasive infections are fatal without early diagnosis and aggressive treatment. ${ }^{82}$ It is recommended that clinicians prescribe voriconazole for treatment of invasive aspergillosis in the CNS. ${ }^{78}$ Results of a 2014 clinical trial indicate that combination therapy with voriconazole and echinocandins may be the most effective antifungal treatment, although future studies are needed to define the role of combination antifungal treatment. ${ }^{83} \mathrm{CNS}$ involvement is associated with a very high mortality rate of up to $50 \%$, despite antifungal treatment. ${ }^{82}$

CANDIDIASIS.-Candida is a natural fungal species in the mouth, gastrointestinal system, and urinary tract. Invasive candidiasis can occur in patients with recent surgical instrumentation, IV drug users, and patients who are immunocompromised, including transplant recipients, patients with HIV/AIDS, infants born prematurely, and those who are neutropenic or have poorly controlled diabetes mellitus. ${ }^{84} \mathrm{CNS}$ involvement almost always occurs in patients with disseminated candidiasis and is seen in the high-risk groups mentioned, particularly premature infants and patients who have had neurosurgery. For neonates and other high-risk patients who have evidence of candiduria or candidemia, an LP and dilated retinal examination should be performed to evaluate for neurologic and eye 
involvement, including signs of vitritis and chorioretinitis. ${ }^{85,86}$ Meningoencephalitis is the most common clinical manifestation of neurocandidiasis, and it can present acutely or chronically. ${ }^{84}$ Unlike other fungal infections, the CSF glucose and white blood cell count may be normal. CSF cultures are more frequently positive in patients with acute meningitis, and the organism is identified in at least $70 \%$ of cases, although culture yield is much lower in those with chronic meningitis. ${ }^{87} \mathrm{CSF}(1,3)$-b-D-glucan is a useful adjunct test that should be sent on patients with high clinical suspicion for CNS Candida infection, although, as mentioned, it is a nonspecific fungal marker. ${ }^{88}$ Mortality is high in patients with CNS involvement, with some studies showing greater than $80 \%$ risk of death. All patients with CNS involvement should receive induction therapy with IV amphotericin B in combination with flucytosine given the high risk of antimicrobial resistance developing in the setting of monotherapy. ${ }^{86}$ The authors recommend that longterm therapy only be discontinued when complete resolution of clinical, CSF, and radiographic abnormalities is seen. ${ }^{86}$

\section{2-2013 US FUNGAL MENINGITIS OUTBREAK ASSOCIATED WITH} STEROID INJECTIONS.-The 2012-2013 US fungal meningitis outbreak, which affected 751 patients and led to 64 deaths, was due to contaminated lots of methylprednisolone acetate used for epidural steroid injections. ${ }^{89}$ Early in the outbreak, patients were noted to have prolonged meningitic symptoms before diagnosis, and several patients had complications, including ischemic and hemorrhagic strokes.$^{90}$ Not only did patients have CNS manifestations of meningitis, but some also developed spinal and paraspinal infections at the injection sites. ${ }^{91,92}$ The pathogen associated with the first reported case was identified as an Aspergillus species, although later cases were associated with the fungus Exserohilum rostratum, which is an environmental mold. Molecular diagnostic studies, including deep sequencing and PCR, were used early in the outbreak and served as important platforms to identify this unique pathogen, which had not been previously described to cause CNS disease in humans. ${ }^{91}$ Another diagnostic assay that was evaluated during the outbreak was CSF (1,3)-b-D-glucan. Elevated levels of CSF (1,3)-b-Dglucan were an important diagnostic aid, and serial CSF (1,3)-b-D-glucan levels correlated with CNS disease outcome during the outbreak. ${ }^{93,94}$ CSF (1,3)-b-D-glucan is now routinely used in cases of suspected fungal meningitis, except for meningitis caused by cryptococcal species. ${ }^{93-95}$ The CDC provided rapid guidance for management during the outbreak, although, given this new clinical entity, the optimal type and duration of antifungal treatment was unknown. Indeed, relapses of fungal meningitis have been identified, prompting reevaluation of treatment recommendations made during the outbreak. ${ }^{96}$ Thus, the US fungal meningitis outbreak had important implications with respect to medication administration safety as well as for the evaluation and treatment of emerging fungal meningitis cases.

\section{Viral Etiologies}

Several viral etiologies of chronic or recurrent meningitis and meningoencephalitis can occur, mostly in immunodeficient patients, including primary HIV infection, cytomegalovirus, herpes simplex virus type 1 (HSV-i) and type 2 (HSV-2), polyomaviruses, enteroviruses, lymphocytic choriomeningitis virus, and mumps virus. ${ }^{97}$ In addition, metagenomic deep sequencing has identified a number of unusual causes of chronic viral 
meningoencephalitis, including Cache Valley virus, arenaviruses, astrovirus, and a breederassociated infection with a novel variegated squirrel Bornavirus ${ }^{26-22}$ A few viral etiologies of chronic meningitis are highlighted here, and epidemiologic and clinical factors associated with these infections are discussed.

PRIMARY HUMAN IMMUNODEFICIENCY VIRUS INFECTION.-Both primary and secondary neurologic manifestations of HIV infection remain significant contributors to morbidity and mortality among patients infected with the virus worldwide. Most chronic meningitis cases in individuals with HIV infection occur in the context of opportunistic infections, such as tuberculous meningitis and cryptococcal meningitis. Chronic meningitis as a manifestation of primary HIV infection, although rare, has most frequently been described around the time of seroconversion. ${ }^{98} \mathrm{HIV}$ is known to invade the CNS very early in infection, within the first few weeks. Indeed, during HIV seroconversion, an aseptic meningitis has been identified in up to $20 \%$ of patients. ${ }^{99-101}$ Typically, CSF shows a mild to moderate lymphocytic pleocytosis, normal glucose, normal or mildly elevated protein, and elevated HIV viral load. ${ }^{101}$ It is important to rule out concurrent opportunistic infections that can also cause chronic meningitis. Current evidence supports the early initiation of ART in the context of acute HIV infection, although this has not been evaluated specifically in patients with CNS manifestations around the time of seroconversion. ${ }^{102}$

HERPES SIMPLEX VIRUS TYPE 2.-HSV-2 is a common cause of acute, chronic, and recurrent meningitis. Primary infection with HSV-2 occurs via two mechanisms. In adults, the infection is sexually transmitted, while in infants, exposure occurs through maternal-fetal vertical transmission. Herpesviruses have a high seroprevalence in the general population, and thus a risk exists across the general population for reactivation of latent infection. ${ }^{103}$ The most common manifestation of HSV-2 is genital lesions, which, notably, may not be present in patients who present with neurologic manifestations. ${ }^{104}$ It is therefore important for clinicians to elicit any remote history of genital lesions. HSV-2 meningitis may occur during primary infection or reactivation, as the virus remains latent in the dorsal root ganglia after initial exposure. ${ }^{105}$ Patients who are immunocompromised have been noted to have more fulminant and severe CNS manifestations. The basic CSF profile is consistent with an aseptic meningitis. CSF HSV-2 PCR is a useful diagnostic marker as it is highly sensitive and specific. ${ }^{104,106}$ A 2015 study showed that patients who are immunosuppressed who develop HSV-2 meningitis may benefit from antiviral treatment for at least 1 week. ${ }^{107}$ Evidence suggests that treatment may not impact outcome in patients who are immunocompetent, although this is predominantly based on small retrospective studies. In one randomized controlled treatment trial, suppressive treatment with valacyclovir showed no effect on the risk of recurrent meningitis, although, notably, the dosage used was lower than some would advocate. ${ }^{108}$

LYMPHOCYTIC CHORIOMENINGITIS VIRUS.-Lymphocytic choriomeningitis virus is found locally in the United States and throughout the world and is associated with rodent exposure. House mice are the most common associated vector, and chronic meningitis associated with lymphocytic choriomeningitis virus is associated with an increased risk of indoor exposure to these rodents. Three modes of transmission are known, including direct 
infection from rodents, via transplanted organs, and by maternal-fetal vertical transmission. Clinically, patients with chronic meningitis typically have a preceding flulike illness a few weeks before the onset of neurologic symptoms. Laboratory clues during this period include an associated leukopenia and thrombocytopenia. ${ }^{109}$ Unlike other viral causes of meningitis, the CSF characteristically shows a marked lymphocytic pleocytosis, which is commonly greater than 1000 cells $/ \mathrm{mm}^{3}$, and a low CSF to serum glucose. ${ }^{110}$ Lymphocytic choriomeningitis virus can be confirmed by culture, although culture is only positive for the first few weeks of infection and is typically negative in patients who present with chronic meningitis. Thus, clinicians often rely on complement fixation or neutralizing antibodies for diagnosis, which are typically positive a few weeks after initial infection and remain positive for a prolonged period. ${ }^{109}$ No antiviral treatment exists for lymphocytic choriomeningitis virus-associated chronic meningitis, and infection typically resolves with symptomatic management.

\section{Bacterial Etiologies}

Although bacteria are most commonly associated with acute meningitis, several bacteria species can lead to a more indolent clinical course. Both Treponema pallidum, and Mycobacterium tuberculosis are important etiologies of chronic meningitis. For more information on T. pallidum, refer to the article "Neuroborreliosis and Neurosyphilis" byJohn J. Halperin, MD, FAAN, FIDSA, ${ }^{111}$ in this issue of Continuum, and for more information on M. tuberculosis, refer to the article "Tuberculosis of the Central Nervous System" by Joseph R. Zunt, MD, MPH, ${ }^{112}$ in this issue of Continuum. Tick-borne organisms, including Ehrlichia, Babesia, and Anaplasma species, constitute an important group of bacteria that can cause chronic meningitis. Other bacterial organisms in the differential include Nocardia, Leptospira, and Brucella species and Listeria monocytogenes. ${ }^{97}$ Leptospirosis and brucellosis are highlighted in this section.

LEPTOSPIROSIS.-Leptospirosis is caused by a spirochete transmitted via the urine or excrement of an infected animal and is most commonly seen in tropical and subtropical regions. Outbreaks have been identified in Southeast Asia, the Caribbean, and South America, with populations particularly susceptible during periods of heavy rains, including monsoons and hurricanes, when water supplies can be easily contaminated. ${ }^{113}$ Outbreaks have occurred in the United States as well, including in a group of people who swam in a contaminated lake during a triathlon in southern Illinois. Acutely, patients may present with a flulike illness, uveitis, and thrombocytopenia (ie, Weil syndrome), with neurologic manifestations, including meningitic symptoms, typically occurring later during the chronic phase. ${ }^{114}$ Neurologic manifestations are rare, although likely underreported as diagnosis at the time when neurologic symptoms typically develop is a major challenge. ${ }^{115}$ A 2014 study highlighted the utility of unbiased metagenomic deep sequencing in diagnosing an immunosuppressed patient with neuroleptospirosis who had negative diagnostic testing by conventional methods. ${ }^{16}$ Although leptospirosis has been classically treated with penicillin, doxycycline, or a cephalosporin, evidence to support or refute antibiotic choice in severe disease is lacking. ${ }^{116}$ 
BRUCELLOSIS.-Brucellosis is found worldwide, with populations at significant risk in the Mediterranean, Middle East, Central America, and South America. Brucella can be transmitted through consumption of undercooked meat or unpasteurized dairy products, via inhalation, or via direct entry through skin wounds or mucous membranes. Hunters and individuals who raise livestock are at significantly high risk of exposure. During the acute phase of illness, the classic clinical presentation includes fluctuating fevers, migratory arthralgia, and excessive sweating. Systemic involvement is most common and includes the musculoskeletal system (including severe back pain due to spondylitis), hepatic system, and genitourinary system. Neurobrucellosis is much rarer and thought to occur in less than 5\% of cases, although it is likely underreported. Making a definitive diagnosis is challenging. The most frequent neurologic manifestations are an isolated meningitis or meningoencephalitis, which may present acutely or chronically. Most cases with neurologic involvement are diagnosed by serologic markers as culture is low yield. ${ }^{117}$ As with neuroleptosporosis, metagenomic deep sequencing was able to diagnose neurobrucellosis in a particularly challenging case ${ }^{20}$ The definitive treatment for neurobrucellosis is unknown, so treatment is extrapolated from data on treatment for systemic brucellosis infection. Typically, treatment involves ceftriaxone or doxycycline and rifampicin in combination for at least 2 months, but extended courses are recommended if clinical, CSF, or radiographic resolution is delayed. ${ }^{118}$

\section{Parasitic Etiologies}

Parasitic etiologies are important to consider in patients with a pertinent epidemiologic history, including individuals who have lived in or traveled to tropical and subtropical regions. Parasitic infections are rare causes of chronic meningitis, but they are important to include in the differential diagnosis. Organisms to consider include Echinococcus, Strongyloides, Acanthamoeba, Angiostrongylus, Taenia solium, Baylisascaris, and Toxoplasma species. ${ }^{97}$

\section{RECURRENT MENINGITIS}

Recurrent meningitis is defined by at least two episodes of meningitis with associated CSF pleocytosis with no symptoms between episodes. ${ }^{119}$ Recurrent meningitis was first described in the 1940s by physician-scientist Pierre Mollaret, who noted a handful of cases of recurrent acute aseptic meningitis with CSF showing evidence of lymphocytic and mononuclear pleocytosis. This was later attributed to HSV-2 infection. ${ }^{120-122}$ The condition was later named Mollaret meningitis after him and the "Mollaret cells" he identified, although it is now known that many of the infectious and noninfectious etiologies of chronic meningitis can occur in a fluctuating pattern consistent with a recurrent meningitis. While triggers for recurrent viral meningitis are unclear, significant risk factors should be investigated in those who present with recurrent bacterial meningitis, including host factors such as anatomic defects that provide a nidus for bacterial CNS invasion (eg, skull-base defects, neural tube defects) and acquired and congenital immunodeficiencies that predispose individuals to recurrent ear, nose, and throat infections. Likewise, recurrent meningitis due to fungi or parasites should trigger an investigation for an underlying immunocompromised state or ongoing environmental exposures. This should go beyond testing for HIV and should include evaluation of T-cell and B-cell profiles, complement 
levels, IgG subclass quantification, and screening for rheumatologic conditions. Recently an association between acute meningoencephalitis infection and positive paraneoplastic antibodies in recurrent meningitis cases was identified, although further studies are required to determine the significance of autoimmune antibodies in recurrent meningitis.

\section{NONINFECTIOUS ETIOLOGIES}

A number of noninfectious causes exist for chronic meningitis, including chemical, autoimmune, inflammatory, or vasculitic etiologies.

\section{Chemical Etiologies}

The main categories of medications associated with chronic meningitis are nonsteroidal antiinflammatory medications (most commonly ibuprofen), IVIg, antimicrobial medications (trimethoprim/sulfamethoxazole), immunosuppressant medications, chemotherapy agents, and anticonvulsants (lamotrigine and carbamazepine). The underlying pathogenesis of druginduced meningitis is not entirely known, but it is thought to be due to meningeal irritation or an immune-mediated hypersensitivity reaction. ${ }^{123}$ Patients who develop drug-induced meningitis most commonly have symptom onset soon after drug exposure, with rapid recovery after medication discontinuation. Other causes of chemical meningitis include benign brain masses, neurosurgical procedures, and subarachnoid hemorrhage. ${ }^{97}$ It is important to note that if a dermoid cyst is suspected, neuroimaging evaluation during a quiescent period may be higher yield as the cyst may be decreased in volume and harder to visualize during the symptomatic period.

\section{Autoimmune, Inflammatory, and Vasculitic Etiologies}

Several autoimmune and inflammatory conditions that mimic an infectious process can lead to chronic meningitis. These cases are particularly challenging to clinicians as patients are often on chronic immunosuppressant medications for treatment of their underlying immunemediated condition, placing them at risk for serious CNS infections. Some autoimmune conditions have a predilection for the leptomeninges or pachymeninges, or both, and have systemic pathognomonic features, which should alert the neurologist evaluating such cases (TABLE 3-1). Autoimmune and inflammatory causes of chronic meningitis include systemic lupus erythematosus, rheumatoid arthritis, Sjogren syndrome, neurosarcoidosis, Behcet syndrome, IgG4-related diseases, Cogan syndrome, Vogt-Koyanagi-Harada syndrome, primary CNS vasculitis, and other autoimmune etiologies of vasculitis. Neurosarcoidosis, IgG4-related diseases, and Vogt-Koyanagi-Harada syndrome are highlighted in this section.

NEUROSARCOIDOSIS.-Sarcoidosis is an inflammatory disorder involving multiple organ systems characterized by non-necrotizing granulomas; the majority of cases have pulmonary involvement. ${ }^{124}$ Clinical manifestations typically occur in middle age, although neurologic involvement can occur at any stage of the disease and may present years after initial systemic symptoms. Neurologic complications occur in up to $10 \%$ of patients and may be the presenting symptom in a significant number of patients. ${ }^{125}$ Leptomeningeal involvement is most frequent in patients presenting with clinical features of chronic meningitis and may be associated with other neurologic manifestations, including cranial 
nerve palsies and pituitary involvement. ${ }^{126}$ Definitive diagnosis is made by histopathologic features, although ancillary CSF and serum evaluations are important. CSF typically shows a mononuclear pleocytosis, elevated protein, and, in some cases, low CSF to serum glucose. CSF angiotensin-converting enzyme should be tested as it is a specific marker for sarcoidosis, although it lacks sensitivity and is positive in less than $40 \%$ of cases. ${ }^{127,128}$ Additional recommendations for systemic workup include whole-body imaging, including consideration of fludeoxyglucose positron emission tomography (FDG-PET) or gallium scan, laboratory tests to evaluate for liver function abnormalities and hypercalcemia, and ophthalmologic evaluation. ${ }^{129,130}$ Steroids are the first-line treatment, although patients with CNS manifestations often require additional immunomodulatory treatment, including tumor necrosis factor-a antagonists such as infliximab. ${ }^{131}$

IgG4-RELATED PACHYMENINGITIS.-IgG4-related diseases involve multiorgan sclerosis and are defined by pathognomonic histopathologic features, including whorls of fibrosing lesions, lymphoplasmacytic infiltration of IgG4-positive plasma cells, and obliteration of vessels. ${ }^{132}$ As a multiorgan disorder, IgG4-related disease often involves the pancreas, bile ducts, and salivary and lacrimal glands. A distinguishing epidemiologic feature of IgG4-related disease is that it most commonly affects older males, which differs from many other inflammatory causes of chronic meningitis. ${ }^{133}$ Neurologic manifestations occur in less than $10 \%$ of cases and typically occur along with systemic manifestations. The most common neurologic manifestations include a pachymeningitis and pituitary gland involvement. ${ }^{134}$ IgG4-related hypertrophic pachymeningitis is diagnosed definitively by biopsy findings showing evidence of IgG4-positive plasma cells along with the pathognomic features described. ${ }^{132}$ Leptomeningeal involvement has also been reported but is rarer than IgG4 infiltration of the dura mater. ${ }^{135}$ Patients most commonly present with headache and multiple cranial neuropathies from mechanical compression. ${ }^{134}$ All patients should have their serum $\mathrm{IgG}_{4}$ level checked, which is elevated in multisystem disease, although if CNS disease occurs in isolation, the serum level may be normal. ${ }^{136}$ The CSF IgG4 level should also be checked and is elevated in some patients with pachymeningeal disease. ${ }^{137}$ No evidence-based approach to management has been established, although the general consensus is to initiate high-dose steroids followed by a prolonged steroid taper, which is extrapolated from management of autoimmune pancreatitis associated with IgG4-related disease. ${ }^{138}$ Rituximab may be considered in patients with recurrence and lack of clinical improvement with steroids, although evidence is lacking on the benefit of steroid-sparing agents in CNS disease. ${ }^{139}$

VOGT-KOYANAGI-HARADA SYNDROME.--Vogt-Koyanagi-Harada syndrome is one of several syndromes known to involve the ocular system and meninges (CASE 3-3). In addition to Vogt-Koyanagi-Harada syndrome, infectious etiologies (eg, catscratch disease, syphilis, Lyme disease, toxoplasmosis), inflammatory conditions (eg, neurosarcoidosis, Behçet syndrome), lymphoma, and paraneoplastic syndromes should be considered in the differential diagnosis of entities that affect the uvea and meninges. ${ }^{140}$ Vogt-KoyanagiHarada syndrome has four distinct clinical phases and is defined by a uveitis associated with serous retinal detachments, disc edema, and vitritis. ${ }^{141}$ Meningitic symptoms are most typical in the prodromal phase before ocular symptoms or signs occur and are associated 
with a lymphocytic CSF pleocytosis. ${ }^{142}$ Other associated symptoms that should be reviewed in all patients with suspicion of Vogt-Koyanagi-Harada syndrome include hearing abnormalities and vertiginous symptoms. Following the neurologic symptoms, patients develop blurring of their vision, often acutely, with an associated granulomatous uveitis in most patients. Later, patients have loss of retinal pigment and ocular scarring. Fluorescein angiography and optical coherence tomography can be particularly useful in these cases. Because of the delay in onset of ophthalmic findings, patients presenting with primary neurologic manifestations, including chronic meningitis, are often misdiagnosed or have a significant delay before receiving a definitive diagnosis, at which time ocular findings are typically irreversible. ${ }^{141}$ Thus, clinicians must evaluate the ocular system in all patients presenting with subacute or chronic meningitis and consider early referral to an ophthalmologist or neuro-ophthalmologist for a dilated funduscopic examination. Current treatment recommendations include a prolonged course of steroids for at least 6 months, although the optimal dosing is not evidence based. ${ }^{143}$ Patients are often placed on long-term steroid-sparing immunosuppressant medications to prevent recurrences. ${ }^{141}$

\section{Carcinomatous Meningitis}

While a detailed discussion of the clinical presentation and management of carcinomatous meningitis is beyond the scope of this article, it is important to mention that metastatic spread of certain solid and hematologic malignancies to the leptomeninges and pachymeninges are important considerations when evaluating a patient with chronic meningitis. Breast cancer, lung cancer, melanoma, lymphoma, and leukemia are the neoplasms that most commonly spread to the meninges. ${ }^{144}$

The basic CSF profile may mimic an infectious process, with elevated CSF white blood cell count, low CSF to serum glucose, and elevated protein. Thus, specific studies to evaluate for possible carcinomatous infiltration of the meninges should be considered, including cytology, flow cytometry, and meningeal biopsy. As with some infectious and autoimmune causes of chronic meningitis, empiric use of adjunctive glucocorticoids can delay and mask the diagnosis of a neoplastic meningitis, particularly lymphoma.

\section{CONCLUSION}

Chronic meningitis remains a significant diagnostic and therapeutic challenge, and despite extensive testing, over one-third of cases remain undiagnosed. Often, serial serologic, CSF, and neuroimaging studies are indicated, although novel diagnostic platforms including metagenomic deep sequencing may hold promise for identifying organisms in these challenging cases. Infectious etiologies are more common in those at risk for disseminated disease, specifically those who are immunocompromised because of HIV/AIDS, transplant recipients, and those on immunosuppressant medications. Noninfectious etiologies, including autoimmune and neoplastic etiologies, should also be considered based on history and examination. Future research is needed to develop more rapid point-of-care testing, assess the clinical utility and impact of novel diagnostic platforms, and evaluate and optimize antimicrobial treatment regimens in chronic meningitis. 


\title{
Acknowledgments
}

\author{
RELATIONSHIP DISCLOSURE:
}

Dr Thakur receives research/grant support from the National Institutes of Health (K23NS105935). Dr Wilson receives research/grant support from Genentech, Inc, and the National Institute of Neurological Disorders and Stroke (K08NS096117).

\section{REFERENCES}

1. Ginsberg L, Kidd D. Chronic and recurrent meningitis. Pract Neurol 2008;8(6):348-361. doi: 10.1136/jnnp.2008.157396. [PubMed: 19015295]

2. Smith JE, Aksamit AJ Jr. Outcome of chronic idiopathic meningitis. Mayo Clin Proc 1994;69(6): 548-556. doi:10.1016/S0025-6196(12)62246-0. [PubMed: 8189760]

3. Hildebrand J, Aoun M. Chronic meningitis: still a diagnostic challenge. J Neurol 2003;250(6): 653660. doi:10.1007/s00415-003-1101-5. [PubMed: 12796824]

4. Biofire. The BioFire FilmArray meningitis/encephalitis (ME) panel. biofiredx.com/filmarrayme/ Accessed August 29, 2018.

5. Wilson MR, O'Donovan BD, Gelfand JM, et al. Chronic meningitis investigated via metagenomic next-generation sequencing [published online ahead of print 4 16, 2018]. JAMA Neurol. doi: 10.1001/jamaneurol.2018.0463.

6. Baldwin K, Zunt JR. Chronic meningitis In: Louis ED, Mayer SA, Rowland LP, editors. Merritt's neurology. 13th ed. Philadelphia, PA: Wolters Kluwer, 2016:526-537.

7. Baldwin K, Whiting C. Chronic meningitis: simplifying a diagnostic challenge. Curr Neurol Neurosci Rep 2016;16(3):30. doi:10.1007/s11910-016-0630-0. [PubMed: 26888190]

8. Baldwin KJ, Zunt JR. Evaluation and treatment of chronic meningitis. Neurohospitalist 2014;4(4): 185-195. doi:10.1177/1941874414528940. [PubMed: 25360204]

9. Smirniotopoulos JG, Murphy FM, Rushing EJ, et al. Patterns of contrast enhancement in the brain and meninges. Radiographics 2007;27(2):525-551. doi:10.1148/rg.272065155. [PubMed: 17374867]

10. Glantz MJ, Cole BF, Glantz LK, et al. Cerebrospinal fluid cytology in patients with cancer: minimizing false-negative results. Cancer 1998;82(4):733-739. doi:10.1002/ (SICI)1097-0142(19980215)82:4<733::AID-CNCR17>3.0.CO;2-Z. [PubMed: 9477107]

11. Wilkinson RJ, Rohlwink U, Misra UK, et al. Tuberculous meningitis. Nat Rev Neurol 2017; 13(10):581-598. doi:10.1038/nrneurol.2017.120. [PubMed: 28884751]

12. Pinto VL Jr, Lima MA, Rolla VC, et al. Atypical cerebrospinal fluid profile in tuberculous meningitis. Trop Doct 2009;39(2):76-78. doi:10.1258/td.2008.080242. [PubMed: 19299285]

13. Cheng TM, O'Neill BP, Scheithauer BW, Piepgras DG. Chronic meningitis: the role of meningeal or cortical biopsy. Neurosurgery 1994;34(4):590-595; discussion 596. doi: 10.1097/00006123-199404000-00004. [PubMed: 8008155]

14. Srinivasan L, Pisapia JM, Shah SS, et al. Can broad-range 16S ribosomal ribonucleic acid gene polymerase chain reactions improve the diagnosis of bacterial meningitis? A systematic review and meta-analysis. Ann Emerg Med 2012;60(5):609.e2-620.e602. doi:10.1016/j.annemergmed. 2012.05.040. [PubMed: 22883680]

15. Meyer T, Franke G, Polywka SK, et al. Improved detection of bacterial central nervous system infections by use of a broad-range PCR assay. J Clin Microbiol 2014;52(5):1751-1753. doi: 10.1128/JCM.00469-14. [PubMed: 24622094]

16. Wilson MR, Naccache SN, Samayoa E, et al. Actionable diagnosis of neuroleptospirosis by nextgeneration sequencing. N Engl J Med 2014; 370(25):2408-2417. doi:10.1056/NEJMoa1401268. [PubMed: 24896819]

17. Frémond ML, Pérot $\mathrm{P}$, Muth E, et al. Next-generation sequencing for diagnosis and tailored Therapy: a case report of astrovirus-associated progressive encephalitis. J Pediatric Infect Dis Soc 2015;4(3): e53-e57. doi:10.1093/jpids/piv040. [PubMed: 26407445] 
18. Naccache SN, Peggs KS, Mattes FM, et al. Diagnosis of neuroinvasive astrovirus infection in an immunocompromised adult with encephalitis by unbiased next-generation sequencing. Clin Infect Dis 2015;60(6):919-923. doi:10.1093/cid/ciu912. [PubMed: 25572898]

19. Quan PL, Wagner TA, Briese T, et al. Astrovirus encephalitis in boy with X-linked agammaglobulinemia. Emerg Infect Dis 2010; 16(6):918-925. doi:10.3201/eid1606.091536. [PubMed: 20507741]

20. Mongkolrattanothai K, Naccache SN, Bender JM, et al. Neurobrucellosis: unexpected answer from metagenomic next-generation sequencing. J Pediatric Infect Dis Soc 2017;6(4):393-398. doi: 10.1093/jpids/piw066. [PubMed: 28062553]

21. Hoffmann B, Tappe D, Hüper D, et al. A variegated squirrel bornavirus associated with fatal human encephalitis. N Engl J Med 2015; 373(2):154-162. doi:10.1056/NEJMoa1415627. [PubMed: 26154788]

22. Wilson MR, Suan D, Duggins A, et al. A novel cause of chronic viral meningoencephalitis: Cache Valley virus. Ann Neurol 2017;82(1):105-114. doi:10.1002/ana.24982. [PubMed: 28628941]

23. Murthy JM, Sundaram C. Fungal infections of the central nervous system. Handb Clin Neurol 2014; 121:1383-1401. doi:10.1016/B978-0-7020-4088-7.00095-X. [PubMed: 24365427]

24. Durski KN, Kuntz KM, Yasukawa K, et al. Costeffective diagnostic checklists for meningitis in resource-limited settings. J Acquir Immune Defic Syndr 2013;63(3):e101-e108. doi:10.1097/QAI. 0b013e31828e1e56. [PubMed: 23466647]

25. Park BJ, Wannemuehler KA, Marston BJ, et al. Estimation of the current global burden of cryptococcal meningitis among persons living with HIV/AIDS. AIDS. 2009;23(4):525-530. doi: 10.1097/QAD.0b013e328322ffac. [PubMed: 19182676]

26. Rajasingham R, Smith RM, Park BJ, et al. Global burden of disease of HIV-associated cryptococcal meningitis: an updated analysis. Lancet Infect Dis 2017;17(8):873-881. doi:10.1016/ S1473-3099(17)30243-8. [PubMed: 28483415]

27. Zhu LP, Wu JQ, Xu B, et al. Cryptococcal meningitis in non-HIV-infected patients in a Chinese tertiary care hospital, 1997-2007. Med Mycol 2010;48(4):570-579. doi: 10.3109/13693780903437876. [PubMed: 20392150]

28. Datta K, Bartlett KH, Baer R, et al. Spread of Cryptococcus gattii into Pacific Northwest region of the United States. Emerg Infect Dis 2009;15(8):1185-1191. doi:10.3201/eid1508.081384. [PubMed: 19757550]

29. Williamson PR, Jarvis JN, Panackal AA, et al. Cryptococcal meningitis: epidemiology, immunology, diagnosis and therapy. Nat Rev Neurol 2017;13(1):13-24. doi:10.1038/nrneurol. 2016.167. [PubMed: 27886201]

30. Lee YC, Wang JT, Sun HY, Chen YC. Comparisons of clinical features and mortality of cryptococcal meningitis between patients with and without human immunodeficiency virus infection. J Microbiol Immunol Infect 2011;44(5):338-345. doi:10.1016/j.jmii.2010.08.011. [PubMed: 21524972]

31. Garlipp CR, Rossi CL, Bottini PV. Cerebrospinal fluid profiles in acquired immunodeficiency syndrome with and without neurocryptococcosis. Rev Inst Med Trop Sao Paulo 1997;39(6):323325. doi:10.1590/S0036-46651997000600003. [PubMed: 9674282]

32. Barenfanger J, Lawhorn J, Drake C. Nonvalue of culturing cerebrospinal fluid for fungi. J Clin Microbiol 2004;42(1):236-238. doi:10.1128/JCM.42.1.236-238.2004. [PubMed: 14715758]

33. Boulware DR, Rolfes MA, Rajasingham R, et al. Multisite validation of cryptococcal antigen lateral flow assay and quantification by laser thermal contrast. Emerg Infect Dis 2014;20(1): 4553. doi:10.3201/eid2001.130906. [PubMed: 24378231]

34. Jarvis JN, Percival A, Bauman S, et al. Evaluation of a novel point-of-care cryptococcal antigen test on serum, plasma, and urine from patients with HIV-associated cryptococcal meningitis. Clin Infect Dis 2011;53(10)4019-1023. doi:10.1093/cid/cir613.

35. Mpoza E, Mukaremera L, Kundura DA, et al. Evaluation of a point-of-care immunoassay test kit 'StrongStep' for cryptococcal antigen detection. PLoS One 2018;13(1):e0190652. doi:10.1371/ journal.pone.0190652. [PubMed: 29304090] 
36. World Health Organization. Consolidated guidelines on the use of antiretroviral drugs for treating and preventing HIV infection: recommendations for a public health approach. 2nd ed. Geneva, Switzerland: World Health Organization, 2016.

37. Wake RM, Britz E, Sriruttan C, et al. High cryptococcal antigen titers in blood are predictive of subclinical cryptococcal meningitis among human immunodeficiency virus-infected patients. Clin Infect Dis 2018;66(5):686-692. doi:10.1093/cid/cix872. [PubMed: 29028998]

38. Boulware DR, Meya DB, Muzoora C, et al. Timing of antiretroviral therapy after diagnosis of cryptococcal meningitis. N Engl J Med 2014; 370(26):2487-2498. doi:10.1056/NEJMoa1312884. [PubMed: 24963568]

39. Molloy SF, Kanyama C, Heyderman RS, et al. Antifungal combinations for treatment of cryptococcal meningitis in Africa. N Engl J Med 2018;378(11):1004-1017. doi:10.1056/ NEJMoa1710922. [PubMed: 29539274]

40. Perfect JR, Dismukes WE, Dromer F, et al. Clinical practice guidelines for the management of cryptococcal disease: 2010 update by the Infectious Diseases Society of America. Clin Infect Dis 2010;50(3):291-322. doi:10.1086/649858. [PubMed: 20047480]

41. Beardsley J, Wolbers M, Kibengo FM, et al. Adjunctive dexamethasone in HIV-associated cryptococcal meningitis. N Engl J Med 2016; 374(6):542-554. doi:10.1056/NEJMoa1509024. [PubMed: 26863355]

42. Macsween KF, Bicanic T, Brouwer AE, et al. Lumbar drainage for control of raised cerebrospinal fluid pressure in cryptococcal meningitis: case report and review. J Infect 2005; 51(4):e221-e224. doi:10.1016/j.jinf.2005.02.010. [PubMed: 16291274]

43. Rolfes MA, Hullsiek KH, Rhein J, et al. The effect of therapeutic lumbar punctures on acute mortality from cryptococcal meningitis. Clin Infect Dis 2014; 59(11):1607-1614. doi:10.1093/cid/ ciu596. [PubMed: 25057102]

44. Pasquier E, Kunda J, De Beaudrap P, et al. Long-term mortality and disability in cryptococcal meningitis: a systematic literature review. Clin Infect Dis 2018; 66(7):1122-1132. doi:10.1093/cid/ cix870. [PubMed: 29028957]

45. Kauffman CA. Histoplasmosis: a clinical and laboratory update. Clin Microbiol Rev 2007;20(1): 115-132. doi:10.1128/CMR.00027-06. [PubMed: 17223625]

46. Cano MV, Hajjeh RA. The epidemiology of histoplasmosis: a review. Semin Respir Infect 2001;16(2):109-118. doi:10.1053/srin.2001.24241. [PubMed: 11521243]

47. DiSalvo AF, Johnson WM. Histoplasmosis in South Carolina: support for the microfocus concept. Am J Epidemiol 1979;109(4):480-492. doi:10.1093/oxfordjournals.aje.a112705. [PubMed: 443245]

48. Baddley JW, Winthrop KL, Patkar NM, et al. Geographic distribution of endemic fungal infections among older persons, United States. Emerg Infect Dis 2011;17(9):1664-1669. doi:10.3201/ eid1709.101987. [PubMed: 21888792]

49. Goodwin RA Jr, Shapiro JL, Thurman GH, et al. Disseminated histoplasmosis: clinical and pathologic correlations. Medicine (Baltimore) 1980;59(1): 1-33. doi: 10.1097/00005792-198001000-00001. [PubMed: 7356773]

50. Livramento JA, Machado LR, Nóbrega JP, et al. Histoplasmosis of the central nervous system: study of cerebrospinal fluid in 8 patients [in Portuguese]. Arq Neuropsiquiatr 1993;51(1):80-86. doi:10.1590/S0004-282X1993000100013. [PubMed: 8215936]

51. Wheat LJ, Batteiger BE, Sathapatayavongs B. Histoplasma capsulatum infections of the central nervous system. A clinical review. Medicine (Baltimore) 1990;69(4):244-260. doi: 10.1097/00005792-199007000-00006. [PubMed: 2197524]

52. Wheat J, Myint T, Guo Y, et al. Central nervous system histoplasmosis: multicenter retrospective study on clinical features, diagnostic approach and outcome of treatment. Medicine (Baltimore) 2018;97(13):e0245. doi:10.1097/MD.0000000000010245. [PubMed: 29595679]

53. Wheat LJ, Freifeld AG, Kleiman MB, et al. Clinical practice guidelines for the management of patients with histoplasmosis: 2007 update by the Infectious Diseases Society of America. Clin Infect Dis 2007;45(7):807-825. [PubMed: 17806045]

54. Saccente M, Woods GL. Clinical and laboratory update on blastomycosis. Clin Microbiol Rev 2010;23(2):367-381. doi:10.1128/CMR.00056-09. [PubMed: 20375357] 
55. Chapman SW, Lin AC, Hendricks KA, et al. Endemic blastomycosis in Mississippi: epidemiological and clinical studies. Semin Respir Infect 1997;12(3):219-228. [PubMed: 9313293]

56. Limper AH, Knox KS, Sarosi GA, et al. An official American Thoracic Society statement: treatment of fungal infections in adult pulmonary and critical care patients. Am J Respir Crit Care Med 2011;183(1):96-128. doi:10.1164/rccm.2008-740ST. [PubMed: 21193785]

57. Gonyea EF. The spectrum of primary blastomycotic meningitis: a review of central nervous system blastomycosis. Ann Neurol 1978; 3(1):26-39. doi:10.1002/ana.410030106. [PubMed: 655652]

58. Bariola JR, Perry P, Pappas PG, et al. Blastomycosis of the central nervous system: a multicenter review of diagnosis and treatment in the modern era. Clin Infect Dis 2010;50(6): 797-804. doi: 10.1086/650579. [PubMed: 20166817]

59. Walkty A, Keynan Y, Karlowsky J, et al. Central nervous system blastomycosis diagnosed using the MVista ${ }^{\circledR}$ Blastomyces quantitative antigen enzyme immunoassay test on cerebrospinal fluid: a case report and review of the literature. Diagn Microbiol Infect Dis 2018;90(2):102-104. doi: 10.1016/j.diagmicrobio.2017.10.015. [PubMed: 29195765]

60. Chapman SW, Dismukes WE, Proia LA, et al. Clinical practice guidelines for the management of blastomycosis: 2008 update by the Infectious Diseases Society of America. Clin Infect Dis 2008;46(12):1801-1812. doi:10.1086/588300. [PubMed: 18462107]

61. Brown J, Benedict K, Park BJ, Thompson GR 3rd. Coccidioidomycosis: epidemiology. Clin Epidemiol 2013;5:185-197. doi:10.2147/CLEP.S34434. [PubMed: 23843703]

62. Galgiani JN, Ampel NM, Blair JE, et al. 2016 Infectious Diseases Society of America (IDSA) clinical practice guideline for the treatment of coccidioidomycosis. Clin Infect Dis 2016;63(6): e112-e146. doi:10.1093/cid/ciw360. [PubMed: 27470238]

63. Williams PL. Coccidioidal meningitis. Ann N Y Acad Sci 2007;1111:377-384. doi:10.1196/ annals.1406.037. [PubMed: 17363442]

64. Bañuelos AF, Williams PL, Johnson RH, et al. Central nervous system abscesses due to Coccidioides species. Clin Infect Dis 1996;22(2): 240-250. doi:10.1093/clinids/22.2.240. [PubMed: 8838179]

65. Mischel PS, Vinters HV. Coccidioidomycosis of the central nervous system: neuropathological and vasculopathic manifestations and clinical correlates. Clin Infect Dis 1995;20(2):400-405. doi: 10.1093/clinids/20.2.400. [PubMed: 7742448]

66. Ragland AS, Arsura E, Ismail Y, Johnson R. Eosinophilic pleocytosis in coccidioidal meningitis: frequency and significance. Am J Med 1993;95(3):254-257. doi:10.1016/0002-9343(93)90276-U. [PubMed: 8368223]

67. Galgiani JN, Ampel NM, Blair JE, et al. Coccidioidomycosis. Clin Infect Dis 2005;41(9): 12171223. doi:10.1086/496991. [PubMed: 16206093]

68. Kassis C, Zaidi S, Kuberski T, et al. Role of coccidioides antigen testing in the cerebrospinal fluid for the diagnosis of Coccidioidal meningitis. Clin Infect Dis 2015;61(10):1521-1526. doi: 10.1093/cid/civ585. [PubMed: 26209683]

69. Pappagianis D, Saito M, Van Hoosear KH. Antibody in cerebrospinal fluid in non-meningitic coccidioidomycosis. Sabouraudia 1972;10(2): 173-179. [PubMed: 4625497]

70. Durkin M, Connolly P, Kuberski T, et al. Diagnosis of coccidioidomycosis with use of the Coccidioides antigen enzyme immunoassay. Clin Infect Dis 2008;47(8):e69-e73. doi: 10.1086/592073. [PubMed: 18781884]

71. Goldstein E, Winship MJ, Pappagianis D. Ventricular fluid and the management of coccidioidal meningitis. Ann Intern Med 1972; 77(2):243-246. doi:10.7326/0003-4819-77-2-243. [PubMed: 4641658]

72. De Pauw B, Walsh TJ, Donnelly JP, et al. Revised definitions of invasive fungal disease from the European Organization for Research and Treatment of Cancer/Invasive Fungal Infections Cooperative Group and the National Institute of Allergy and Infectious Diseases Mycoses Study Group (EORTC/MSG) Consensus Group. Clin Infect Dis 2008;46(12): 1813-1821. doi: 10.1086/588660. [PubMed: 18462102] 
73. Maschmeyer G Invasive aspergillosis in severely immunosuppressed patients: significant progress, but many unresolved problems. Transpl Infect Dis 2008;10(3):151-155. doi:10.1111/j. 1399-3062.2008.00308.x. [PubMed: 18489674]

74. Guermazi A, Gluckman E, Tabti B, Miaux Y. Invasive central nervous system aspergillosis in bone marrow transplantation recipients: an overview. Eur Radiol 2003;13(2):377-388. doi:10.1007/ s00330-002-1480-5. [PubMed: 12599004]

75. McCarthy M, Rosengart A, Schuetz AN, et al. Mold infections of the central nervous system. N Engl J Med 2014;371(2):150-160. doi:10.1056/NEJMra1216008. [PubMed: 25006721]

76. Antinori S, Corbellino M, Meroni L, et al. Aspergillus meningitis: a rare clinical manifestation of central nervous system aspergillosis. Case report and review of 92 cases. J Infect 2013;66(3):218238. doi:10.1016/j.jinf.2012.11.003. [PubMed: 23178421]

77. McGinnis MR. Detection of fungi in cerebrospinal fluid. Am J Med 1983;75(1B): 129-138. doi: 10.1016/0002-9343(83)90084-0.

78. Patterson TF, Thompson GR 3rd, Denning DW, et al. Practice guidelines for the diagnosis and management of aspergillosis: 2016 update by the Infectious Diseases Society of America. Clin Infect Dis 2016;63(4):e1-e60. doi:10.1093/cid/ciw326. [PubMed: 27365388]

79. Arvanitis M, Anagnostou T, Mylonakis E. Galactomannan and polymerase chain reaction-based screening for invasive aspergillosis among high-risk hematology patients: a diagnostic metaanalysis. Clin Infect Dis 2015;61(8): 1263-1272. doi:10.1093/cid/civ555. [PubMed: 26157047]

80. Imbert S, Brossas JY, Palous M, et al. Performance of aspergillus PCR in cerebrospinal fluid for the diagnosis of cerebral aspergillosis. Clin Microbiol Infect 2017;23(11):889.e1-889.e884. doi: 10.1016/j.cmi.2017.06.012. [PubMed: 28642144]

81. Lamoth F Galactomannan and 1,3 $\beta$-d-glucan testing for the diagnosis of invasive aspergillosis. $\mathbf{J}$ Fungi (Basel) 2016;2(3).pii:E22. doi:10.3390/jof2030022. [PubMed: 29376937]

82. Kohno S High mortality in invasive aspergillosis: what we need to know for determination of poor prognosis and next countermeasures. Clin Infect Dis 2008;47(9):1185-1187. doi:10.1086/592256. [PubMed: 18808362]

83. Réminiac F, Sonneville R, Massias L, et al. Very-high-dose caspofungin combined with voriconazole to treat central nervous system aspergillosis: substantial penetration of caspofungin into cerebrospinal fluid. Antimicrob Agents Chemother 2014;58(6):3568-3569. doi:10.1128/AAC. 02719-14. [PubMed: 24733459]

84. Góralska K, Blaszkowska J, Dzikowiec M. Neuroinfections caused by fungi [published online ahead of print 5 21, 2018]. Infection. doi:10.1007/s15010-018-1152-2.

85. Oude Lashof AM, Rothova A, Sobel JD, et al. Ocular manifestations of candidemia. Clin Infect Dis 2011;53(3):262-268. doi:10.1093/cid/cir355. [PubMed: 21765074]

86. Pappas PG, Kauffman CA, Andes DR, et al. Clinical practice guideline for the management of candidiasis: 2016 update by the Infectious Diseases Society of America. Clin Infect Dis 2016; 62(4):e1-e50. doi:10.1093/cid/civ933. [PubMed: 26679628]

87. Fernandez M, Moylett EH, Noyola DE, Baker CJ. Candidal meningitis in neonates: a 10-year review. Clin Infect Dis 2000;31(2):458-463. doi:10.1086/313973. [PubMed: 10987705]

88. Lyons JL, Erkkinen MG, Vodopivec I. Cerebrospinal fluid (1,3) ${ }^{2}$-D-glucan in isolated Candida meningitis. Clin Infect Dis 2015;60(1): 161-162. doi:10.1093/cid/ciu737. [PubMed: 25228700]

89. Abbas KM, Dorratoltaj N, O'Dell ML, et al. Clinical response, outbreak investigation, and epidemiology of the fungal meningitis epidemic in the United States: systematic review. Disaster Med Public Health Prep 2016;10(1):145-151. doi:10.1017/dmp.2015.137. [PubMed: 26681583]

90. Chiller TM, Roy M, Nguyen D, et al. Clinical findings for fungal infections caused by methylprednisolone injections. N Engl J Med 2013;369(17):1610-1619. doi:10.1056/ NEJMoa1304879. [PubMed: 24152260]

91. Kauffman CA, Pappas PG, Patterson TF. Fungal infections associated with contaminated methylprednisolone injections. N Engl J Med 2013;368(26):2495-2500. doi:10.1056/ NEJMra1212617. [PubMed: 23083312]

92. Kainer MA, Reagan DR, Nguyen DB, et al. Fungal infections associated with contaminated methylprednisolone in Tennessee. N Engl J Med 2012;367(23):2194-2203. doi:10.1056/ NEJMoa1212972. [PubMed: 23131029] 
93. Lyons JL, Roos KL, Marr KA, et al. Cerebrospinal fluid (1,3) $\beta$-D-glucan detection as an aid for diagnosis of iatrogenic fungal meningitis. J Clin Microbiol 2013;51(4):1285-1287. doi:10.1128/ JCM.00061-13. [PubMed: 23363831]

94. Litvintseva AP, Lindsley MD, Gade L, et al. Utility of (1-3)²-D-glucan testing for diagnostics and monitoring response to treatment during the multistate outbreak of fungal meningitis and other infections. Clin Infect Dis 2014;58(5): 622-630. doi:10.1093/cid/cit808. [PubMed: 24336827]

95. Lyons JL, Thakur KT, Lee R, et al. Utility of measuring (1,3)2-d-glucan in cerebrospinal fluid for diagnosis of fungal central nervous system infection. J Clin Microbiol 2015;53(1):319-322. doi: 10.1128/JCM.02301-14. [PubMed: 25378578]

96. Smith RM, Tipple M, Chaudry MN, et al. Relapse of fungal meningitis associated with contaminated methylprednisolone. N Engl J Med 2013;368(26):2535-2536. doi:10.1056/ NEJMc1306560. [PubMed: 23718153]

97. Cho TA, Venna N. Management of acute, recurrent, and chronic meningitides in adults. Neurol Clin 2010;28(4):1061-1088. doi:10.1016/j.ncl.2010.03.023. [PubMed: 20816277]

98. Schacker T, Collier AC, Hughes J, et al. Clinical and epidemiologic features of primary HIV infection. Ann Intern Med 1996;125(4): 257-264. doi: 10.7326/0003-4819-125-4-199608150-00001. [PubMed: 8678387]

99. Valcour V, Chalermchai T, Sailasuta N, et al. Central nervous system viral invasion and inflammation during acute HIV infection. J Infect Dis 2012;206(2):275-282. doi:10.1093/infdis/ jis326. [PubMed: 22551810]

100. Hellmuth J, Fletcher JL, Valcour V, et al. Neurologic signs and symptoms frequently manifest in acute HIV infection. Neurology 2016;87(2):148-154. doi:10.1212/WNL.0000000000002837. [PubMed: 27287217]

101. Newton PJ, Newsholme W, Brink NS, et al. Acute meningoencephalitis and meningitis due to primary HIV infection. BMJ 2002;325(7374): 1225-1227.

102. INSIGHT START Study Group, Lundgren JD, Babiker AG, et al. Initiation of antiretroviral therapy in early asymptomatic HIV infection. N Engl J Med 2015;373(9):795-807. doi:10.1056/ NEJMoa1506816. [PubMed: 26192873]

103. Bradley H, Markowitz LE, Gibson T, McQuillan GM. Seroprevalence of herpes simplex virus types 1 and 2--United States, 1999-2010. J Infect Dis 2014;209(3):325-333. doi:10.1093/infdis/ jit458. [PubMed: 24136792]

104. Schlesinger Y, Tebas P, Gaudreault-Keener M, et al. Herpes simplex virus type 2 meningitis in the absence of genital lesions: improved recognition with use of the polymerase chain reaction. Clin Infect Dis 1995;20(4):842-848. doi:10.1093/clinids/20.4.842. [PubMed: 7795083]

105. Landry ML, Greenwold J, Vikram HR. Herpes simplex type-2 meningitis: presentation and lack of standardized therapy. Am J Med 2009;122(7):688-691. doi:10.1016/j.amjmed.2009.02.017. [PubMed: 19559173]

106. Guffond T, Dewilde A, Lobert PE, et al. Significance and clinical relevance of the detection of herpes simplex virus DNA by the polymerase chain reaction in cerebrospinal fluid from patients with presumed encephalitis. Clin Infect Dis 1994;18(5):744-749. doi:10.1093/clinids/18.5.744. [PubMed: 8075263]

107. Noska A, Kyrillos R, Hansen G, et al. The role of antiviral therapy in immunocompromised patients with herpes simplex virus meningitis. Clin Infect Dis 2015;60(2):237-242. doi: 10.1093/cid/ciu772. [PubMed: 25273082]

108. Aurelius E, Franzen-Röhl E, Glimåker M, et al. Long-term valacyclovir suppressive treatment after herpes simplex virus type 2 meningitis: a double-blind, randomized controlled trial. Clin Infect Dis 2012;54(9):1304-1313. doi:10.1093/cid/cis031. [PubMed: 22460966]

109. Wilson MR, Peters CJ. Diseases of the central nervous system caused by lymphocytic choriomeningitis virus and other arenaviruses. Handb Clin Neurol 2014;123:671-681. doi: 10.1016/B978-0-444-53488-0.00033-X. [PubMed: 25015511]

110. Bonthius DJ, Karacay B. Meningitis and encephalitis in children. An update. Neurol Clin 2002;20(4):1013-1038, vi-vii. doi:10.1016/S0733-8619(02)00016-6. [PubMed: 12616679]

111. Halperin JJ. Neuroborreliosis and neurosyphilis. Continuum (Minneap Minn) 2018;24(5, Neuroinfectious Disease):1439-1458. [PubMed: 30273247] 
112. Zunt JR. Tuberculosis of the central nervous system. Continuum (Minneap Minn) 2018; 24(5, Neuroinfectious Disease):1422-1438. [PubMed: 30273246]

113. Terpstra WJ, Ligthart GS, Schoone GJ. ELISA for the detection of specific IgM and IgG in human leptospirosis. J Gen Microbiol 1985;131(2): 377-385. doi:10.1099/00221287-131-2-377. [PubMed: 3981131]

114. Mathew T, Satishchandra P, Mahadevan A, et al. Neuroleptospirosis - revisited: experience from a tertiary care neurological centre from south India. Indian J Med Res 2006;124(2):155-162. [PubMed: 17015929]

115. Levett PN, Branch SL, Whittington CU, et al. Two methods for rapid serological diagnosis of acute leptospirosis. Clin Diagn Lab Immunol 2001;8(2): 349-351. doi:10.1128/CDLI. 8.2.349-351.2001. [PubMed: 11238220]

116. Brett-Major DM, Coldren R. Antibiotics for leptospirosis. Cochrane Database Syst Rev 2012; (2):CD008264. doi:10.1002/14651858.CD008264.pub2. [PubMed: 22336839]

117. Buzgan T, Karahocagil MK, Irmak H, et al. Clinical manifestations and complications in 1028 cases of brucellosis: a retrospective evaluation and review of the literature. Int J Infect Dis 2010;14(6): e469-e478. doi:10.1016/j.ijid.2009.06.031. [PubMed: 19910232]

118. Pappas G, Akritidis N, Christou L. Treatment of neurobrucellosis: what is known and what remains to be answered. Expert Rev Anti Infect Ther 2007;5(6):983-990. doi: 10.1586/14787210.5.6.983. [PubMed: 18039082]

119. Rosenberg J, Galen BT. Recurrent meningitis. Curr Pain Headache Rep 2017;21(7):33. doi: 10.1007/s11916-017-0635-7. [PubMed: 28551737]

120. Chan TY, Parwani AV, Levi AW, Ali SZ. Mollaret's meningitis: cytopathologic analysis of fourteen cases. Diagn Cytopathol 2003;28(5):227-231. doi:10.1002/dc.10261. [PubMed: 12722116]

121. Shalabi M, Whitley RJ. Recurrent benign lymphocytic meningitis. Clin Infect Dis 2006; 43(9): 1194-1197. doi:10.1086/508281. [PubMed: 17029141]

122. Tedder DG, Ashley R, Tyler KL, Levin MJ. Herpes simplex virus infection as a cause of benign recurrent lymphocytic meningitis. Ann Intern Med 1994;121(5):334-338. doi: 10.7326/0003-4819-121-5-199409010-00004. [PubMed: 8042822]

123. Yelehe-Okouma M, Czmil-Garon J, Pape E, et al. Drug-induced aseptic meningitis: a minireview. Fundam Clin Pharmacol 2018;32(3):252-260. doi:10.1111/fcp.12349. [PubMed: 29364542]

124. Fahim A, Mann JS. Pulmonary sarcoidosis: diagnostic and treatment update. Expert Rev Respir Med 2014;8(4):493-501. doi:10.1586/17476348.2014.919225. [PubMed: 24832794]

125. Zajicek JP, Scolding NJ, Foster O, et al. Central nervous system sarcoidosis-diagnosis and management. QJM 1999;92(2):103-117. doi:10.1093/qjmed/92.2.103. [PubMed: 10209662]

126. Allen RK, Sellars RE, Sandstrom PA. A prospective study of 32 patients with neurosarcoidosis. Sarcoidosis Vasc Diffuse Lung Dis 2003;20(2):118-125. [PubMed: 12870721]

127. Oksanen V, Fyhrquist F, Grönhagen-Riska C, Somer H. CSF angiotensin-converting enzyme in neurosarcoidosis. Lancet 1985;1(8436):1050-1051. doi:10.1016/S0140-6736(85)91658-7.

128. Dale JC, O'Brien JF. Determination of angiotensin-converting enzyme levels in cerebrospinal fluid is not a useful test for the diagnosis of neurosarcoidosis. Mayo Clin Proc 1999;74(5):535. doi:10.4065/74.5.535. [PubMed: 10319092]

129. Huang JF, Aksamit AJ, Staff NP. MRI and PET imaging discordance in neurosarcoidosis. Neurology 2012;79(10):1070. doi:10.1212/WNL.0b013e3182684672. [PubMed: 22946115]

130. Culver DA. Diagnosing sarcoidosis. Curr Opin Pulm Med 2015;21(5):499-509. doi:10.1097/ MCP.0000000000000201. [PubMed: 26176972]

131. Moravan M, Segal BM. Treatment of CNS sarcoidosis with infliximab and mycophenolate mofetil. Neurology 2009;72(4):337-340. doi:10.1212/01.wnl.0000341278.26993.22. [PubMed: 19171830]

132. Deshpande V, Zen Y, Chan JK, et al. Consensus statement on the pathology of IgG4-related disease. Mod Pathol 2012;25(9):1181-1192. doi:10.1038/modpathol.2012.72. [PubMed: 22596100] 
133. Kanno A, Masamune A, Okazaki K, et al. Nationwide epidemiological survey of autoimmune pancreatitis in Japan in 2011. Pancreas 2015;44(4):535-539. doi:10.1097/MPA. 0000000000000325. [PubMed: 25815647]

134. Lu LX, Della-Torre E, Stone JH, Clark SW. IgG4-related hypertrophic pachymeningitis: clinical features, diagnostic criteria, and treatment. JAMA Neurol 2014;71(6):785-793. doi:10.1001/ jamaneurol.2014.243. [PubMed: 24733677]

135. Boban J, Ardali S, Thurnher MM. Leptomeningeal form of immunoglobulin G4-related hypertrophic meningitis with perivascular spread: a case report and review of the literature [published online ahead of print 5 7, 2018]. Neuroradiology. doi:10.1007/s00234-018-2028-y.

136. Carruthers MN, Khosroshahi A, Augustin T, et al. The diagnostic utility of serum IgG4 concentrations in IgG4-related disease. Ann Rheum Dis 2015;74(1):14-18. doi:10.1136/ annrheumdis-2013-204907. [PubMed: 24651618]

137. Della-Torre E, Passerini G, Furlan R, et al. Cerebrospinal fluid analysis in immunoglobulin G4related hypertrophic pachymeningitis. J Rheumatol 2013;40(11):1927-1929. doi:10.3899/jrheum. 130678. [PubMed: 24187161]

138. Kamisawa T, Okazaki K, Kawa S, et al. Japanese consensus guidelines for management of autoimmune pancreatitis: III. Treatment and prognosis of AIP. J Gastroenterol 2010;45(5): 471477. doi:10.1007/s00535-010-0221-9. [PubMed: 20213336]

139. Khosroshahi A, Carruthers MN, Deshpande V, et al. Rituximab for the treatment of IgG4-related disease: lessons from 10 consecutive patients. Medicine (Baltimore) 2012;91(1):57-66. doi: 10.1097/MD.0b013e3182431ef6. [PubMed: 22210556]

140. Brazis PW, Stewart M, Lee AG. The uveo-meningeal syndromes. Neurologist 2004;10(4):171184. doi:10.1097/01.nrl.0000131145.26326.ff. [PubMed: 15245583]

141. O'Keefe GA, Rao NA. Vogt-Koyanagi-Harada disease. Surv Ophthalmol 2017;62(1):1-25. doi: 10.1016/j.survophthal.2016.05.002. [PubMed: 27241814]

142. Rao NA, Sukavatcharin S, Tsai JH. Vogt-Koyanagi-Harada disease diagnostic criteria. Int Ophthalmol 2007;27(2-3):195-199. doi:10.1007/s10792-006-9021-x. [PubMed: 17384920]

143. Errera MH, Fardeau C, Cohen D, et al. Effect of the duration of immunomodulatory therapy on the clinical features of recurrent episodes in Vogt-Koyanagi-Harada disease. Acta Ophthalmol 2011;89(4):e357-e366. doi:10.1111/j.1755-3768.2010.02055.x. [PubMed: 21251241]

144. Le Rhun E, Taillibert S, Chamberlain MC. Carcinomatous meningitis: leptomeningeal metastases in solid tumors. Surg Neurol Int 2013;4(suppl 4):S265-S288. doi:10.4103/2152-7806.111304.

[PubMed: 23717798] 


\section{KEY POINTS}

- $\quad$ Establishing a cause of chronic meningitis and providing timely targeted treatment are major challenges for clinicians as many identified infectious agents are rare, and noninfectious etiologies, including medications, neuroinflammatory conditions, toxins, and malignancies, can mimic infections.

- $\quad$ Diagnostic testing should be guided by a thorough history, including assessment of epidemiologic factors and physical examination findings. Often, several serologic, CSF, and neuroimaging studies are indicated.

- The development of novel noninvasive diagnostic techniques, including multiplex polymerase chain reaction; $16 \mathrm{~s}, 18 \mathrm{~s}$, and $28 \mathrm{~s}$ ribosomal RNA polymerase chain reaction; and metagenomic deep sequencing, allows for broad pathogen testing and is an exciting scientific frontier.

- $\quad$ Because of the frequently indolent nature of the symptoms associated with chronic meningitis, the rare and diverse infectious causes, and the significant number of noninfectious etiologies, empiric treatment for chronic meningitis is not broadly recommended. Instead, it is recommended that empiric therapy be initiated on a case-by-case basis after weighing the risks and benefits associated with antimicrobial therapy and the potential for a worsening clinical course.

- Cryptococcus remains the most common fungal etiology of chronic meningitis globally.

- $\quad$ Aggressive measures to decrease intracranial pressure improve survival in cryptococcal meningitis by up to $70 \%$. Despite this, therapeutic lumbar punctures are underutilized. Despite antifungal treatment, studies have shown that the long-term mortality in cryptococcal meningitis is at least $25 \%$.

- $\quad \operatorname{CSF}(1,3)-\beta$-D-glucan was evaluated as a diagnostic assay in the US fungal meningitis outbreak associated with steroid injections. Elevated levels of CSF $(1,3)-\beta$-D-glucan were an important diagnostic aid during the outbreak, and serial CSF $(1,3)-\beta$-D-glucan levels correlated with CNS disease outcome. CSF (1,3)- $\beta$-D-glucan is now routinely used in cases of suspected fungal meningitis, except for meningitis caused by cryptococcal species.

- The US fungal meningitis outbreak had important implications with respect to medication administration safety as well as the evaluation and treatment of emerging fungal meningitis cases.

- Several viral etiologies of chronic meningitis and meningoencephalitis exist, including primary human immunodeficiency virus type 1 infection, cytomegalovirus, herpes simplex virus type 1 and type 2, polyomaviruses, enteroviruses, lymphocytic choriomeningitis virus, and mumps virus. In addition, metagenomic deep sequencing has identified a number of unusual 
causes of chronic viral meningoencephalitis in patients who are immunocompromised.

- Most chronic meningitis cases in individuals with human immunodeficiency virus (HIV) infection occur in the context of opportunistic infections, namely tuberculous meningitis and cryptococcal meningitis. Chronic meningitis as a manifestation of primary HIV infection, although rare, has most frequently been described around the time of seroconversion.

- Herpes simplex virus type 2 is a common cause of acute, chronic, and recurrent meningitis.

- $\quad$ Although bacteria are most commonly associated with acute meningitis, several bacteria species can lead to a more indolent clinical course. Both Treponema pallidum and Mycobacterium tuberculosis are important etiologies of chronic meningitis.

- Tick-borne organisms, including Ehrlichia, Babesia, and Anaplasma species, constitute an important group of bacteria that can cause chronic meningitis. Other bacterial organisms in the differential include Nocardia, Leptospira, Brucella species, and Listeria monocytogenes.

- $\quad$ Parasitic etiologies are important to consider in patients with a pertinent epidemiologic history, including individuals who have lived in or traveled to tropical and subtropical regions. Typically, parasitic infections are rare causes of chronic meningitis, but they are important to include in the differential diagnosis. Organisms to consider include Echinococcus, Strongyloides, Acanthamoeba, Angiostrongylus, Taenia solium, Baylisascaris, and Toxoplasma species.

- The main categories of medications associated with chronic meningitis include nonsteroidal anti-inflammatory medications, IVIg, antimicrobial medications, immunosuppressant medications, chemotherapy agents, and anticonvulsants.

- Several autoimmune and inflammatory conditions that mimic an infectious process can lead to a chronic meningitis. These cases are particularly challenging to clinicians as patients are often on chronic immunosuppressant medications for treatment of their underlying immune-mediated condition, placing them at risk for serious central nervous system infections.

- The most common neurologic manifestations of IgG4-related disease include a pachymeningitis or pituitary gland involvement.

- Vogt-Koyanagi-Harada syndrome is one of several syndromes known to involve the ocular system and meninges.

- Metastatic spread of certain solid and hematologic malignancies to the leptomeninges and pachymeninges are important considerations when evaluating a patient with chronic meningitis. 


\section{CASE 3-1}

A 20-year-old man presented with 2 months of right-sided headaches and 1 week of double vision. On examination, he was noted to have a right cranial nerve VI palsy, papilledema, and meningismus. MRI showed evidence of subtle leptomeningeal enhancement and a small extraaxial subcentimeter focus of enhancement at the interpeduncular fossa (FIGURE 3-3). A lumbar puncture was performed, with opening pressure of $42 \mathrm{~mm} \mathrm{H}_{2} \mathrm{O}$, white blood cell count 320 cells $/ \mathrm{mm}^{3}$ (90\% lymphocytes), glucose $38 \mathrm{mg} / \mathrm{dL}$ (with a normal serum glucose), and protein $77 \mathrm{mg} / \mathrm{dL}$. Cryptococcal antigen in the CSF was positive. He was negative for human immunodeficiency virus (HIV) infection, and an identified risk factor for cryptococcal infection was that he had a pet parakeet in his home. He was started on amphotericin B and flucytosine for induction therapy and had serial therapeutic lumbar punctures. He was then transitioned to oral fluconazole. He had resolution of his headaches and double vision 2 weeks after initiation of treatment.

\section{COMMENT}

Cryptococcus neoformans is found in bird excrement, highlighting the importance of taking a thorough history to discover that this patient had a pet parakeet. Examination findings were consistent with increased intracranial pressure. Cryptococcal antigen in the CSF is highly sensitive and specific, and it led to the diagnosis in this patient. Serial therapeutic lumbar punctures are essential to decrease intracranial pressure, along with antifungal treatment with amphotericin B and flucytosine for induction treatment. 


\section{CASE 3-2}

A 29-year-old man presented with reduced vision in the right eye, an ipsilateral relative afferent pupillary defect, and near-complete ophthalmoplegia. He had been in excellent health until 1 year before presentation, when he developed persistent right facial paresthesia and difficulty seeing from his right eye. He did not seek medical attention at the time, and the symptoms continued. Six months later, he developed chronic frontal predominant headaches, nausea, and generalized fatigue. The patient was originally from Egypt but moved to the United States 1 year ago.

On examination, he had loss of sensation in the right cornea, upper eyelid, and forehead and proptosis on the right side. He was also noted to have weakness of his left arm and leg. MRI showed a right temporal process with edema, mass effect, and contrast enhancement, also involving the right cavernous sinus and originating in the right nasal cavity (FIGURE 3-4). The patient underwent endonasal biopsy, with pathology consistent with granulomatous infection secondary to Aspergillus. He was treated with voriconazole followed by partial resection and debridement. He had serial neuroimaging that showed interval resolution of intracranial spread.

\section{COMMENT}

Sino-orbitai-cerebrai aspergillosis more commonly occurs in immunocompetent hosts and presents in a subacute or chronic manner. Contiguous spread can occur from granulomatous lesions in the paranasal sinuses leading to the development of granulomatous disease, typically in the frontal and temporal lobe, as in this case. Voriconazole is the treatment of choice. 


\section{CASE 3-3}

A 19-year-old man presented to the hospital with 1 month of diffuse holocephalic headaches, meningismus, nausea, vomiting, and fever up to $39^{\circ} \mathrm{C}\left(103^{\circ} \mathrm{F}\right)$. Initial imaging showed evidence of leptomeningeal enhancement. Lumbar puncture results showed a mild lymphocytic pleocytosis, mildly elevated protein, and normal CSF to serum glucose ratio. CSF Gram stain and cultures were negative. One week after initial presentation, he experienced the progressive onset of blurry vision over 3 days. Ophthalmologic examination revealed dense vitritis, optic disc edema with hemorrhages, serous retinal detachment, and granular retinal lesions, worse in the left eye, leading to the overall clinical diagnosis of panuveitis with vasculitis (FIGURE 3-5). He was diagnosed with Vogt-Koyanagi-Harada syndrome based on ocular and neurologic symptoms and treated with steroids with clinical improvement.

\section{COMMENT}

Vogt-Koyanagi-Harada syndrome is one of several syndromes known to involve the uvea, retina, and meninges. It is a T-cell-mediated autoimmune disease that causes a number of cutaneous, ocular, and neurologic symptoms. Neurologic symptoms are usually limited to meningismus, with imaging consistent with leptomeningeal disease. This precedes a bilateral panuveitis that can develop into chronic UVeitis and severe visual deterioration if not promptly treated. 


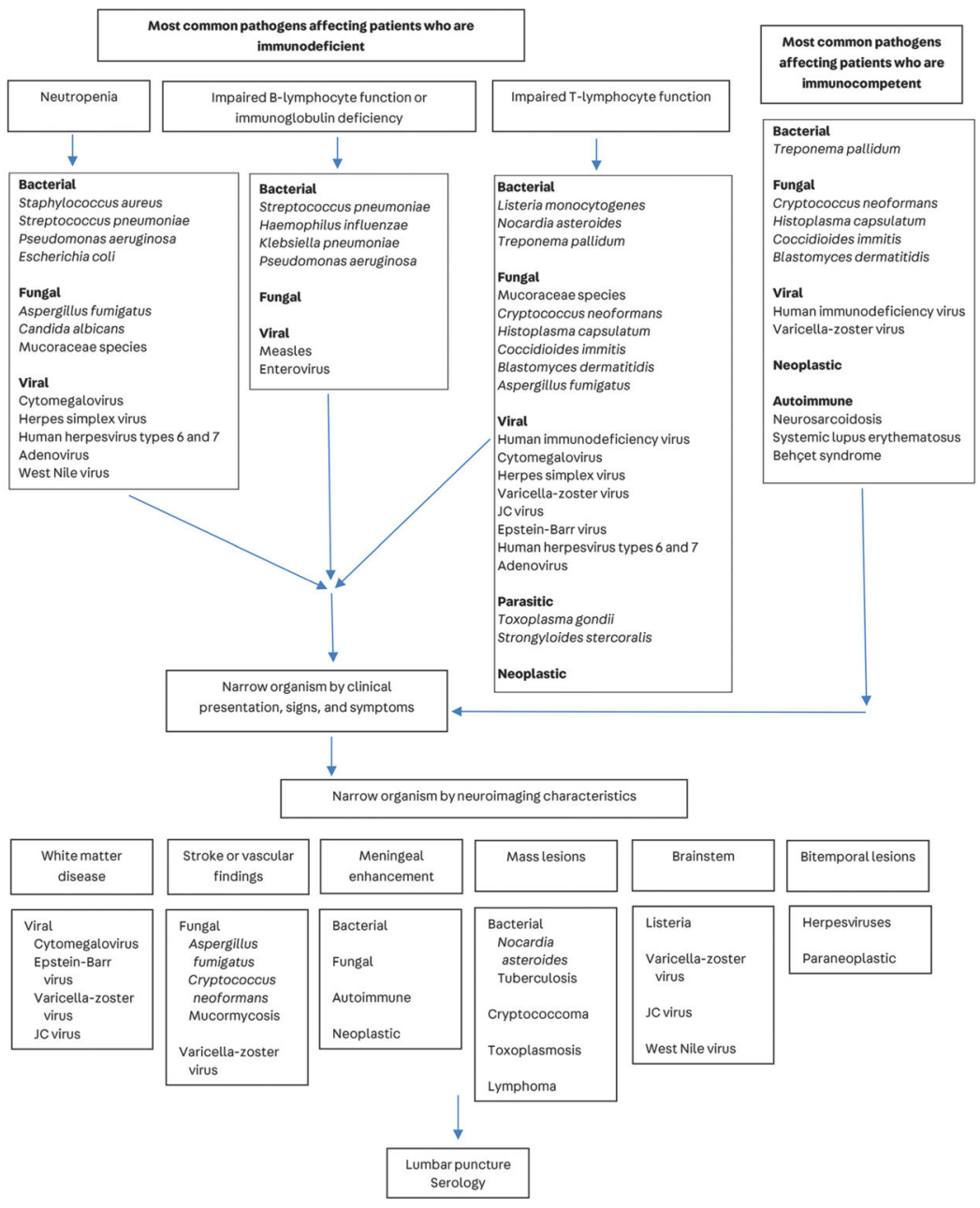

FIGURE 3-1. Diagnostic evaluation approach for chronic meningitis.

Data from Pruitt A, Continuum (Minneap Minn). (C) 2012 American Academy of Neurology. Modified with permission from Baldwin KJ, Zunt JR, Neurohospitalist. ${ }^{8}$ () 2014 SAGE Publications. 
A

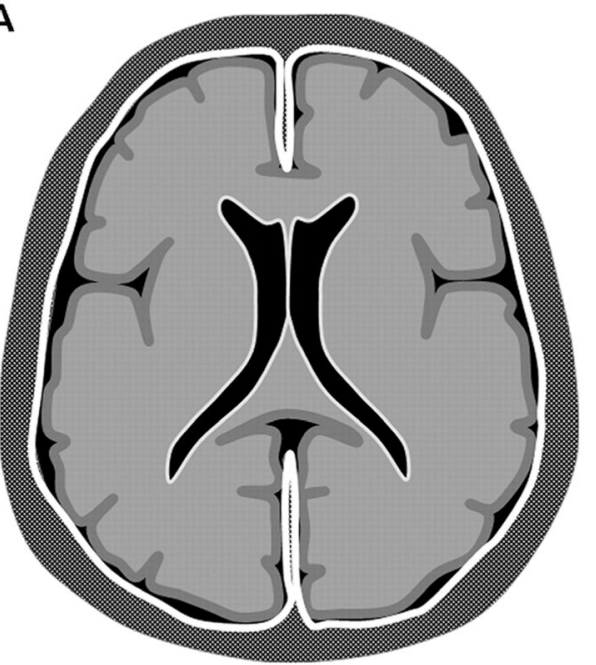

B

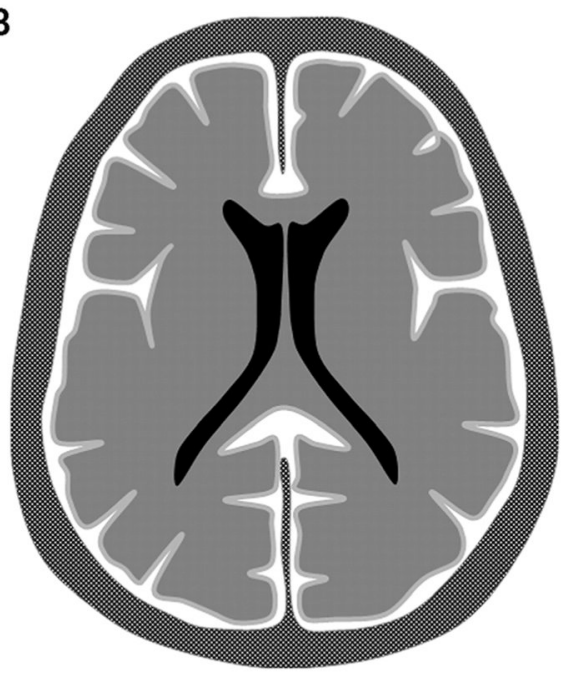

FIGURE 3-2. Patterns of meningeal enhancement in chronic meningitis. $A$, Dura-arachnoid pachymeningeal enhancement. $B$, Pia-arachnoid leptomeningeal enhancement.

Reprinted with permission from Smirniotopoulos JG, et al, Radiographics. ${ }^{9}$ @ 2007 Radiological Society of North America. 


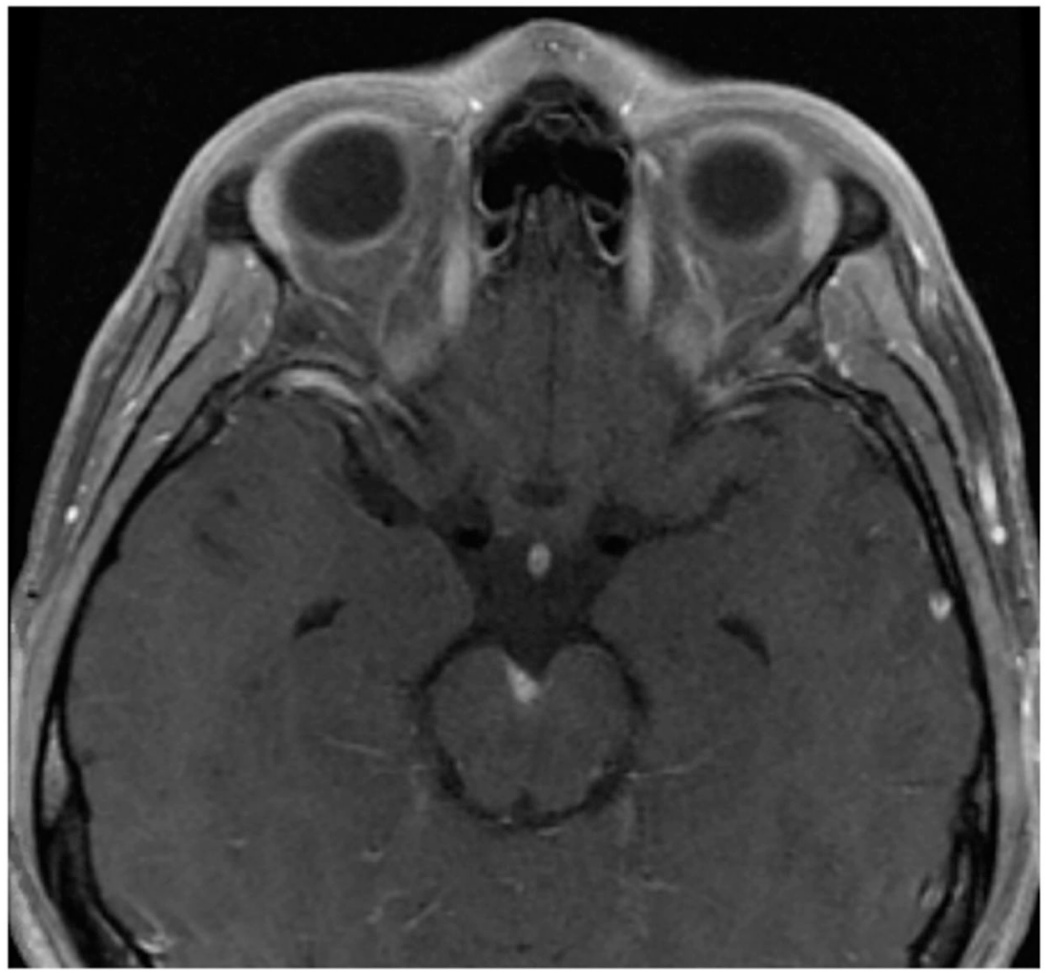

FIGURE 3-3.

Imaging of the patient in CASE 3-1. Axial postcontrast T1-weighted image showing evidence of a small extraaxial subcentimeter focus of enhancement at the interpeduncular fossa. 

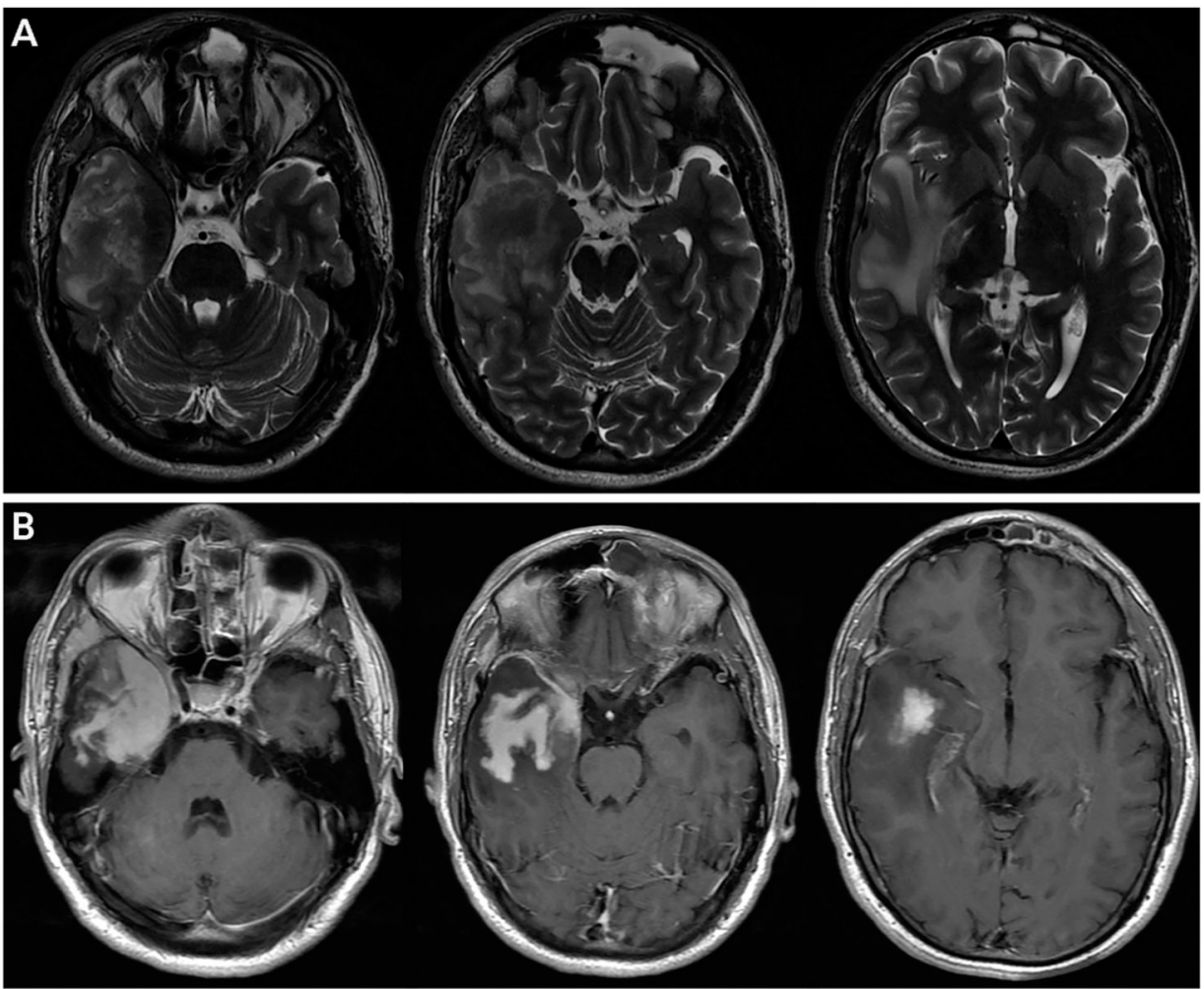

\section{FIGURE 3-4.}

Imaging of the patient in CASE 3-2. Axial T2-weighted MRI $(A)$ and postcontrast T1weighted MRI $(B)$ images showing a large infiltrating, avidly enhancing process with both right temporal extraaxial and intraaxial components, with associated reactive edema and mass effect. Enhancement abuts the right cavernous sinus and involves the right orbital apex. The mass originates from the right posterior nasal cavity with extension through the expanded pterygopalatine fossa with extension inferiorly into the infratemporal fossa involving the temporalis and lateral pterygoid musculature and superiorly through the foramen ovale. 


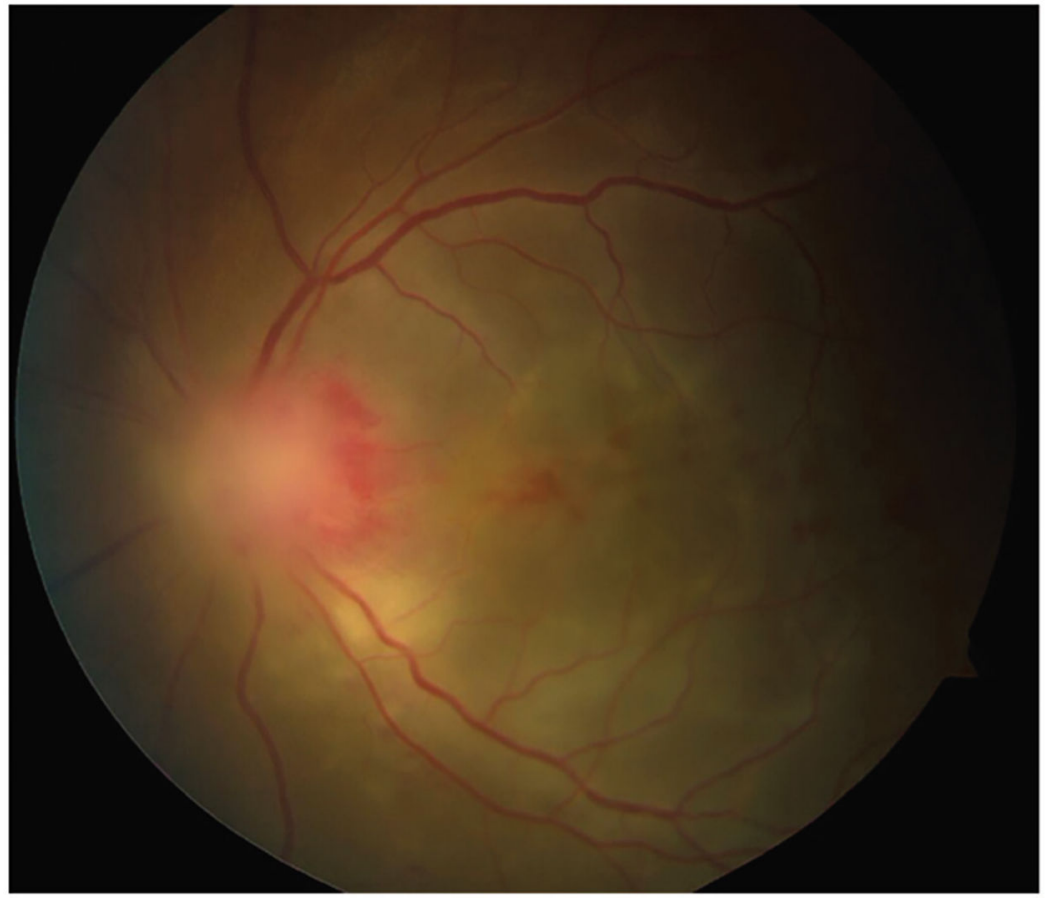

FIGURE 3-5.

Funduscopy of the patient in CASE 3-3 shows dense vitritis, optic disc edema with hemorrhages, serous retinal detachment, and granular retinal lesions. 


\section{TABLE 3-1}

Systemic Diagnostic Clues in Chronic Meningitis ${ }^{a}$

\begin{tabular}{|c|c|c|c|}
\hline Condition & Neurologic Presentation & Systemic Symptoms & Neuroimaging \\
\hline Cryptococcosis & $\begin{array}{l}\text { Headache and fever }(75 \%) \text {, nausea and } \\
\text { vomiting }(50 \%) \text {, altered mental status } \\
(50 \%) \text {, visual symptoms, seizures }\end{array}$ & $\begin{array}{l}\text { Pulmonary, multiorgan } \\
\text { involvement }\end{array}$ & $\begin{array}{l}\text { Hydrocephalus, cerebral edema, } \\
\text { leptomeningeal enhancement, } \\
\text { cryptococcomas }\end{array}$ \\
\hline Coccidioidomycosis & $\begin{array}{l}\text { Headache }(75 \%) \text {; nausea and vomiting } \\
(40 \%) \text {; altered mental status ( } 39 \% \text { to } 73 \%) \text {; } \\
\text { focal neurologic deficits, including ataxia, } \\
\text { gait disturbance, diplopia, or facial palsies } \\
(33 \% \text { to } 80 \%) \text {; nuchal rigidity }(20 \%)\end{array}$ & Pulmonary, lymph nodes, skin & $\begin{array}{l}\text { Hydrocephalus, meningeal } \\
\text { enhancement, nodular } \\
\text { enhancement, basilar meningitis, } \\
\text { cerebral infarction }\end{array}$ \\
\hline Blastomycosis & $\begin{array}{l}\text { Focal neurologic deficits, seizures, altered } \\
\text { mental status } \\
\text { Less common: fever, headache, } \\
\text { meningismus }\end{array}$ & $\begin{array}{l}\text { Pulmonary, verrucous or fungating } \\
\text { skin lesions, bones, joints, } \\
\text { genitourinary system }\end{array}$ & $\begin{array}{l}\text { Single or multiple abscesses, } \\
\text { granulomas, meningeal } \\
\text { enhancement, epidural } \\
\text { extensions and overlying } \\
\text { osteomyelitis }\end{array}$ \\
\hline Histoplasmosis & Headache, altered mental status & $\begin{array}{l}\text { Acute pulmonary infection with } \\
\text { fever, chills, and pulmonary } \\
\text { opacities; multiorgan, including } \\
\text { bone marrow }\end{array}$ & $\begin{array}{l}\text { Normal, granulomas, meningeal } \\
\text { enhancement }\end{array}$ \\
\hline Aspergillosis & $\begin{array}{l}\text { Solitary mass lesion, cavernous sinus } \\
\text { thrombosis, multiple intracranial abscesses, } \\
\text { acute or chronic basilar meningitis, } \\
\text { vasculitis, myelitis }\end{array}$ & $\begin{array}{l}\text { Pulmonary, sinusitis, multiorgan } \\
\text { involvement }\end{array}$ & $\begin{array}{l}\text { Multiple abscesses, meningeal } \\
\text { enhancement, infarction, } \\
\text { hemorrhage, sinusitis with } \\
\text { extension }\end{array}$ \\
\hline Tuberculosis & $\begin{array}{l}\text { Headache, vomiting, meningeal signs, focal } \\
\text { deficits, vision loss, cranial nerve palsies }\end{array}$ & $\begin{array}{l}\text { Pulmonary, malaise, anorexia, } \\
\text { fatigue, weight loss, fever, myalgia }\end{array}$ & $\begin{array}{l}\text { Enhancement of the basilar } \\
\text { meninges, thick exudates, } \\
\text { obstructive hydrocephalus, } \\
\text { miliary pattern, tuberculomas, } \\
\text { periventricular infarcts }\end{array}$ \\
\hline Syphilis & $\begin{array}{l}\text { Meningitis (headache, photophobia, nausea } \\
\text { and vomiting, cranial nerve deficits), } \\
\text { general paresis, psychiatric illness, cognitive } \\
\text { decline, tabes dorsalis, vascular disease }\end{array}$ & $\begin{array}{l}\text { Genital ulcers, fever, } \\
\text { lymphadenopathy, headache, } \\
\text { malaise, myalgia, a macular or } \\
\text { pustular rash of the palms and } \\
\text { soles, multiorgan involvement }\end{array}$ & $\begin{array}{l}\text { Leptomeningeal enhancement, } \\
\text { white matter disease in the brain } \\
\text { and posterior columns, ischemic } \\
\text { stroke }\end{array}$ \\
\hline Borreliosis & $\begin{array}{l}\text { Early: septic lymphocytic meningitis, } \\
\text { cranial neuritis, painful polyradiculitis } \\
\text { Late: myelitis, encephalitis, neurobehavioral } \\
\text { changes }\end{array}$ & $\begin{array}{l}\text { Rash, fever, diffuse aches and } \\
\text { pains, headaches, malaise, fatigue, } \\
\text { carditis }\end{array}$ & $\begin{array}{l}\text { White matter edema with } \\
\text { enhancement }\end{array}$ \\
\hline
\end{tabular}

${ }^{a}$ Reprinted with permission from Baldwin K, Zunt JR. ${ }^{6}$ @ 2016 Lippincott Williams \& Wilkins. 
TABLE 3-2

\section{Differential Diagnosis of Pachymeningeal Enhancement}

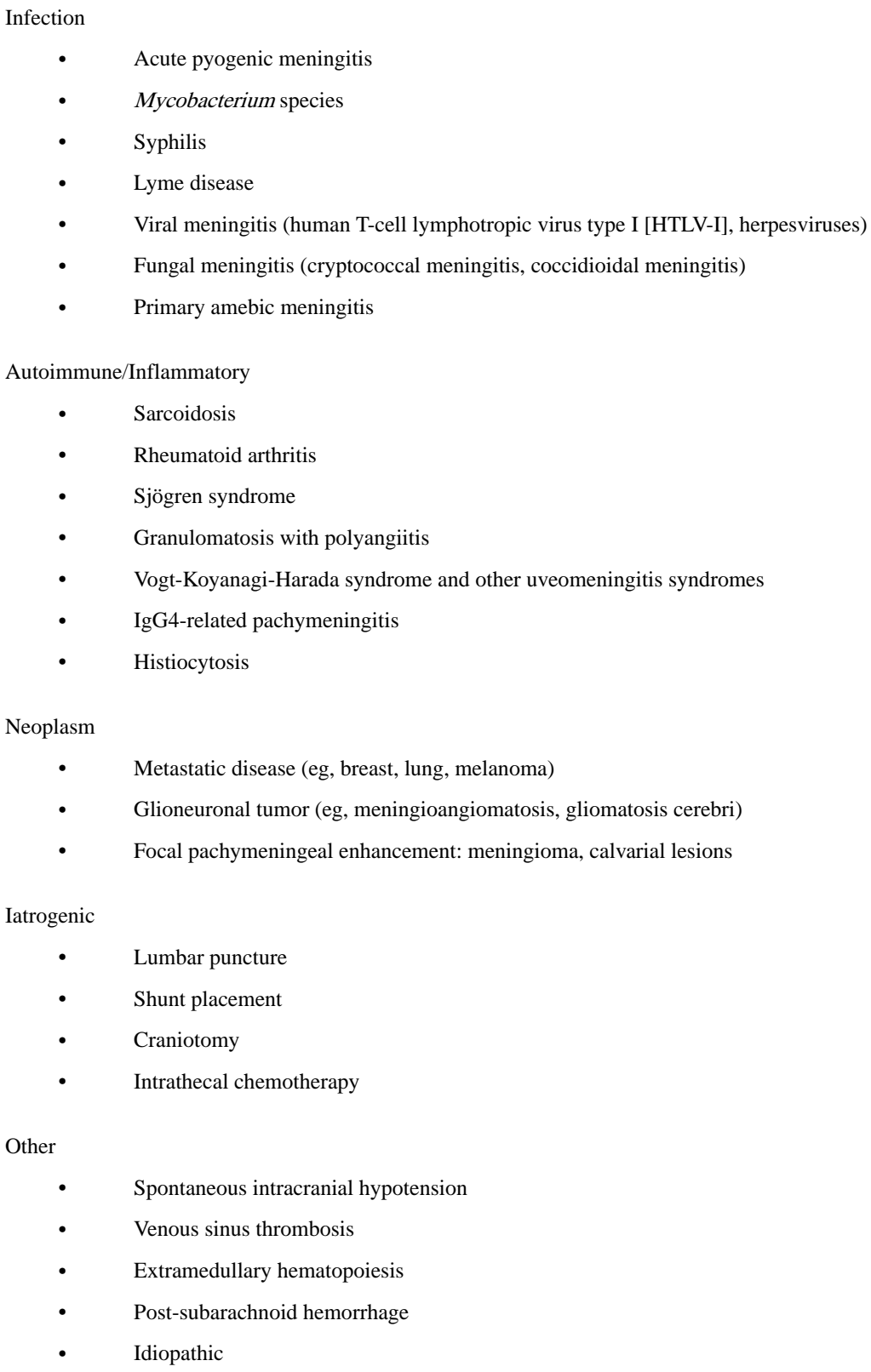

- $\quad$ Focal pachymeningeal enhancement: meningioma, calvarial lesions

IgG4 = immunoglobulin G4. 
TABLE 3-3

\section{Differential Diagnosis of Leptomeningeal Enhancement}

Infection

- $\quad$ Acute pyogenic meningitis

- $\quad$ Viral meningitis

- $\quad$ Syphilis

- Basilar predominant: listeriosis, tuberculous meningitis, endemic fungi, amebic meningitis

Autoimmune/Inflammatory

- $\quad$ Sarcoidosis

- Behçet disease

- Vogt-Koyanagi-Harada syndrome and other uveomeningitis syndromes

- $\quad$ IgG4-related disorders

- Histiocytosis

Neoplasm

- Leptomeningeal carcinomatosis

- Diffuse leptomeningeal glioneuronal tumor

IgG4 = immunoglobulin G4 